\title{
Ni dejar hacer ni dejar pasar: el compromiso de las instituciones bancarias peruanas frente al lavado de activos a través de la implementación de una metodología por riesgo \\ Don't let it happen nor let it go: the commitment of \\ Peruvian banking institutions against money laundering through the implementation of an AML risk assessment methodology
}

\section{ANTONIO DE LA HAZA BARRANTES** \\ Pontificia Universidad Católica del Perú}

\section{BEATRIZ AGUEDO HUIZA*** \\ Pontificia Universidad Católica del Perú}

\section{MELANY ROSALES VICENTE \\ Pontificia Universidad Católica del Perú}

Resumen: El presente artículo propone el marco básico de lo que debería comprender una metodología de identificación y evaluación por riesgo en prevención de lavado de activos para las empresas de operaciones múltiples, en especial los bancos que forman parte del sistema financiero nacional, con el objetivo de identificar aquellas transacciones que podrán estar vinculadas con operaciones de lavado de activos y que deberían ser objeto de reporte de operación sospechosa a la Unidad de Inteligencia Financiera del Perú. Al mismo tiempo, se resalta la función de los bancos como parte de la estructura económica de la sociedad, ya que son las entidades representativas del sistema financiero las que sostienen la confianza de las personas naturales que la conforman. En tal sentido, se analiza, a través de un enfoque basado en riesgos desde la perspectiva de una empresa bancaria y en conformidad con la normativa nacional e internacional, la aplicación de una metodología de identificación y evaluación de riesgos que descansa principalmente en el principio de conocimiento del cliente.

* $\quad$ El presente artículo ha sido elaborado como parte del trabajo «Ni dejar hacer ni dejar pasar: el compromiso de las instituciones bancarias peruanas frente al lavado de activos y la lucha contra la corrupción», del Centro de Investigación, Capacitación y Asesoría Jurídica del Departamento de Derecho de la Pontificia Universidad Católica del Perú.

** Antonio de la Haza Barrantes es abogado por la Pontificia Universidad Católica del Perú, Máster en Derecho Empresarial por la Universidad de Lima, Doctor en Derecho por la Pontificia Universidad Católica del Perú y profesor de la misma casa de estudios.

Código ORCID: 0000-0002-4650-8120. Correo electrónico: antonio.delahaza@gmail.com

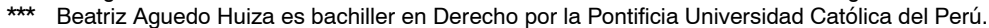
Código ORCID: 0000-0001-8780-9918. Correo electrónico: beatriz.ageuedo@gmail.com

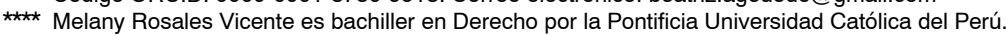
Código ORCID: 0000-0002-8375-5796. Correo electrónico: melany.rv@gmail.com 
Palabras clave: lavado de activos, riesgo, bancos, sistema financiero, enfoque basado en riesgos, metodología, principio de conocimiento del cliente

\begin{abstract}
This article proposes the basic framework of what should be a methodology for identification and risk assessment in the prevention of money laundering for multiple operations companies, especially the banks that are part of the national financial system, with the objective of identifying those transactions that may be linked to asset laundering operations and should be subject to a suspicious transaction report to the Financial Intelligence Unit of Peru. At the same time, it highlights the role of banks as part of the economic structure of society, since they are the representative entities of the financial system, which is why they support people's confidence in the integrity of the system. In this sense, the risk-based approach is analyzed from the perspective of a banking company, so that, in accordance with national and international regulations, they can reinforce the methodology for risk identification and evaluation, based mainly on the principle «know your costumer».
\end{abstract}

Key words: money laundering, banks, financial system, risk-based approach, principle «know your costumer»

CONTENIDO: I. INTRODUCCIÓN.- II. SISTEMA NACIONAL DE PREVENCIÓN DE LAVADO DE ACTIVOS.- II.1. RELACIÓN ENTRE LOS BANCOS Y EL LAVADO DE ACTIVOS.- II.2. EL ROL DE LOS BANCOS FRENTE AL LAVADO DE ACTIVOS.- III. LOS BANCOS Y SU COMPROMISO EN EL SISTEMA DE PREVENCIÓN DE LAVADO DE ACTIVOS.- III.1. ESTADÍSTICA NACIONAL DE REPORTE DE OPERACIONES SOSPECHOSAS POR LAVADO DE ACTIVOS EN EL PERÚ.- III.2. LA CORRUPCIÓN EN EL CONTEXTO PERUANO.- III.2.1. CORRUPCIÓN COMO REFERENTE DEL LAVADO DE ACTIVOS.- III.2.2. PERCEPCIÓN DE LA CORRUPCIÓN POR LA CIUDADANÍA.IV. NUESTRA PROPUESTA: UNA METODOLOGÍA DE IDENTIFICACIÓN Y EVALUACIÓN POR RIESGOS EN PREVENCIÓN DE LAVADO DE ACTIVOS.IV.1. RIESGO DE LAVADO DE ACTIVOS.- IV.1.1. CLIENTE.- IV.1.1.1. PRINCIPIO DE CONOCIMIENTO DEL CLIENTE.- IV.1.2. PRODUCTO Y SERVICIOS.IV.1.3. CANALES.- IV.1.4. UBICACIÓN GEOGRÁFICA.- IV.2. UMBRAL DE GESTIÓN POR RIESGO-- IV.3. APLICACIÓN DE CONTROLES.- IV.4. MONITOREO DEL RIESGO LA/FT.- V. ANEXO.- V.1. PRESENTACIÓN DEL CASO.- V.2. METODOLOGÍA DE IDENTIFICACIÓN Y EVALUACIÓN DE RIESGOS EN PREVENCIÓN DE LAVADO DE ACTIVOS.- VI. CONCLUSIONES.

Nadie sueña con lo que no le interesa. Hermann Hesse

I. INTRODUCCIÓN

La Superintendencia de Banca Seguros y AFP (SBS), a través de la Unidad de Inteligencia Financiera (UIF-Perú) presentó los resultados de la Evaluación Nacional de Riesgos de Lavado de Activos y Financiamiento del Terrorismo (en adelante, nos referiremos al 
lavado de activos y financiamiento del terrorismo con las siglas LA/ FT), documento elaborado con el apoyo del Banco Interamericano de Desarrollo (BID). Su objetivo fue identificar las vulnerabilidades y riesgos que afectan a nuestro país mediante una evaluación de la naturaleza y características de las instituciones peruanas a fin de detectar debilidades estructurales que faciliten la ejecución de operaciones de lavado de activos o financiamiento del terrorismo.

A partir de la lectura del documento, uno de los puntos más reveladores fue el referido a la tolerancia y permisibilidad de la corrupción pública. La evaluación concluía, de manera categórica, que «las conductas delictivas asociadas a la corrupción pública se consideran por amplios segmentos de la población como algo intrínseco al desempeño de potestades administrativas, estimándola como un peaje que debe abonarse para la obtención de servicios públicos» (SBS \& BID, 2016, p. 20). Esta cruda descripción de nuestra realidad representa una triste característica estructural de nuestro país: la transigente actitud de la ciudadanía con respecto al fenómeno de la corrupción, alimentada por la incapacidad del Estado de combatirla adecuadamente, ya sea en su detección, prevención o juzgamiento.

Dado el presente escenario, la comunidad académica debe expresar su rechazo a esta permisividad, en la medida que nuestro rol como intérpretes del derecho nos da herramientas para la creación y aplicación de las normas jurídicas necesarias para tomar acción frente a la pasividad que nos rodea. En los próximos años, los bancos se centrarán en mejorar la experiencia del cliente y en los cambios digitales, pero para ello se requiere de una mixtura entre el negocio y riesgos controlados. Finalmente, lo que un banco busca es un equilibrio entre crecimiento sostenido, adecuada gestión de riesgo, nivel de capital apropiado y fuentes de financiamiento estable y diversificado.

Por ende, la gestión integral del riesgo de prevención de lavado de activos debe ser considerada parte integral de las buenas prácticas y de las políticas corporativas, al ser un proceso continuo que permite identificar eventos potenciales de pérdida. Por esta razón se define la estrategia y el apetito por el riesgo para proveer una seguridad razonable en el logro de los objetivos empresariales. El contar con una «Metodología de identificación y evaluación por riesgo en prevención de lavado de activos» implica también que la empresa bancaria cuente con un sistema de organización interno que delimite las responsabilidades, el grado de interrelación entre las áreas involucradas y el grado de exposición al riesgo que la empresa está dispuesta a asumir en el desarrollo de su objeto social.

Frente a la realidad descrita y en relación con estas consideraciones, corresponde desarrollar nuestro marco teórico referencial. Asimismo,

NI DEJAR HACER NI DEJAR PASAR: EL COMPROMISO DE LAS INSTITUCIONES BANCARIAS

PERUANAS FRENTE AL LAVADO

DE ACTIVOS A

TRAVÉS DE LA

IMPLEMENTACIÓN

DE UNA

METODOLOGÍA

POR RIESGO

DON'T LET IT

HAPPEN NOR

LET IT GO:THE

COMMITMENT

OF PERUVIAN

BANKING

INSTITUTIONS

AGAINST MONEY

LAUNDERING

THROUGHTHE

IMPLEMENTATION

OF AN AML RISK

ASSESSMENT

METHODOLOGY 
a las entidades bancarias les toca reforzar sus controles internos contra el lavado de activos, cumpliendo no solamente con los requerimientos legales dentro del Plan Nacional de Lucha Contra el Lavado de Activos y Financiamiento del Terrorismo, sino, adicionalmente, con la finalidad de proteger al sector financiero de ser utilizado por los lavadores que contaminan nuestra sociedad.

El desarrollo de la presente investigación dentro de un marco teórico busca demostrar la finalidad por la cual una empresa bancaria nacional implementa una metodología de identificación y evaluación por riesgo en prevención de lavado de activos. Por otro lado, es oportuno mencionar que, si bien es cierto que el delito de lavado de activos en la legislación peruana es un delito autónomo que no requiere de la comisión de un delito precedente como el narcotráfico, terrorismo, delitos contra la administración pública, secuestro, proxenetismo, tráfico de menores y defraudación tributaria, entre otros tipos penales para que una persona sea condenada por lavado de activos; para la presente investigación el tema de la corrupción lo consideramos partiendo del lavado de activos como delito económico.

A continuación, expondremos la referencia teórica de la presente investigación. Nuestro marco teórico descansa sobre el objetivo general de explicar el alcance del riesgo de lavado de activos para una empresa bancaria. Asimismo, se apoya sobre dos objetivos específicos relacionados con desarrollar la finalidad de contar con un sistema nacional de prevención de lavado de activos y los componentes de gestión del riesgo que conforman el referido sistema. En todo momento tuvimos como pregunta de investigación saber si el Estado había contribuido con el desarrollo de una metodología de identificación y evaluación del riesgo en prevención de lavado de activos.

Todo lo anterior dio pie a nuestra indagación en torno a si las empresas bancarias nacionales proponen un sistema financiero confiable mediante la implementación de una metodología de identificación y evaluación de riesgo en prevención de lavado de activos.

\section{SISTEMA NACIONAL DE PREVENCIÓN DE LAVADO DE ACTIVOS}

En nuestro país se ha aprobado el Plan Nacional de Lucha Contra el Lavado de Activos y Financiamiento del Terrorismo (en adelante, el Plan Nacional ALA/CFT) mediante el decreto supremo 057-2011-PCM. El Plan Nacional ALA/CFT es una guía para el fortalecimiento del sistema de prevención de lavado de activos y financiamiento del terrorismo, que aborda la necesidad de reforma legislativa y reglamentaria y la adecuación de recursos y capacidades de las instituciones públicas. Su finalidad 
principal es «proteger la integridad y estabilidad del sistema económico financiero, reducir el poder económico del crimen organizado y contribuir a la lucha contra la corrupción» (Plan Nacional ALA/CFT, 2011, p. 12), labor que se realiza a través de tres componentes: la prevención, la detección y la represión penal. El primero apunta a la protección del sistema económico financiero y no financiero para evitar que este sea usado con fines delictivos a través de controles que el Estado y el sector privado deben implementar, tales como el ejercicio de la capacidad supervisora y sancionatoria a nivel administrativo y el establecimiento de obligaciones para la implementación de políticas y procedimientos de detección. La detección consiste en la misma identificación de posibles actividades de lavado, para lo cual la Unidad de Inteligencia Financiera (UIF-Perú) recibe los informes de operaciones sospechosas de los sujetos obligados a reportarle. Finalmente, la represión penal se refiere al ejercicio de la potestad sancionadora del Estado mediante el juzgamiento, la entrega de una pena o sanción y al decomiso de los activos involucrados (Plan Nacional ALA/CFT, 2011, p. 13).

Las empresas del sector financiero forman parte del proceso en la etapa de prevención y detección mediante sus procedimientos orientados a adoptar políticas internas para evitar filtraciones de casos de lavado en los sistemas operativos. Asimismo, deben informar a la UIF-Perú los casos de operaciones sospechosas que hayan detectado en la tarea de identificación o monitoreo de sus clientes.

Frente a lo manifestado en los párrafos anteriores, los bancos a nivel mundial, independientemente del modelo de banca que hubieren optado — sea el de la banca múltiple o la banca especializada 1 constituyen uno de los sectores económicos más regulados. Esto se debe a que la empresa bancaria como tal ha dejado de pertenecer solamente a sus accionistas, desde una perspectiva económica, al constituirse en el canal por el que se aplica la política monetaria de un país ${ }^{2}$, justificando la intervención del Estado en la regulación, por ejemplo, del capital mínimo para las empresas del sistema financiero, los principios contables y de auditoría, la normativa de control y supervisión, etcétera. En el caso del Perú, conforme a la legislación vigente contenida en la ley 26702, Ley General del Sistema Financiero y del Sistema de Seguros y Orgánica de la Superintendencia de Banca y Seguros, y sin haber reconocido en

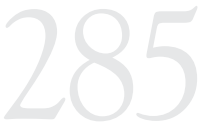

NI DEJAR HACER NI DEJAR PASAR: EL COMPROMISO DE LAS INSTITUCIONES BANCARIAS PERUANAS FRENTE AL LAVADO

DE ACTIVOS A

TRAVÉS DE LA

IMPLEMENTACIÓN

DE UNA

METOdOLOgÍA

POR RIESGO

DON'T LET IT

HAPPEN NOR

LET IT GO:THE

COMMITMENT

OF PERUVIAN

BANKING

INSTITUTIONS

AGAINST MONEY

LAUNDERING

THROUGHTHE

IMPLEMENTATION

OF AN AML RISK

ASSESSMENT

METHODOLOGY

1 La aplicación de uno u otro modelo responde al criterio de la unificación de los servicios financieros. En caso el propósito sea que se otorgue por una sola entidad, hablaríamos de un modelo de banca múltiple. Si por el contrario, varias empresas prestasen un solo producto cada una, como si se tratase de compartimentos estancos aislados, estaríamos frente a un modelo de banca especializada, donde prima la especialización por mandato de la ley antes que una especialización derivada de las propias demandas del mercado que es el fundamento de la banca múltiple.

2 En la Constitución Política del Perú, se indica en forma expresa que «el Estado fomenta y garantiza el ahorro. La Ley establece las obligaciones y los límites de las empresas que reciben ahorros del público, así como el modo y los alcances de dicha garantía» (Constitución Política del Perú, 1993). 
forma expresa un modelo de banca, podemos afirmar hoy que responde a uno de banca múltiple 3 .

En este contexto de regulación, los países desarrollados, entre ellos los que forman parte del G-204 como foro de cooperación en temas relacionados al sistema financiero internacional tanto de países industrializados como emergentes y en especial los Estados Unidos, han entendido que el lavado de activos —independientemente de los tipos penales - va más allá de un asunto exclusivamente moral. Esto es así porque comprende la estabilidad del sistema económico que está llamado a brindar el modelo liberal capitalista.

Un ejemplo de esto es que, en el mundo globalizado actual, no hay transacción comercial que no pase por un banco corresponsal en los Estados Unidos. Ello implica, dentro de la lógica que se promueve ahora para la autoridad americana, considerar que si la transacción pasa por territorio americano y tiene por destino algún otro país no cooperante en temas de prevención, los EE.UU. automáticamente es competente para detener la transacción, congelando el dinero hasta que se determine con claridad el origen y destino de los fondos. Entonces, si bien es cierto que los EE.UU. no tiene competencia para interferir en las transacciones llevadas a cabo en otras jurisdicciones —además de su deber de respetar la soberanía de cada país-, en los hechos ocurre lo contrario. Otro ejemplo de esto lo constituye la llamada Ley FATCA (Foreign Account Tax Compliance Act $)^{5}$ que «tiene por propósito establecer un sistema de fiscalización y retención del impuesto extra-jurisdiccional que afecta principalmente a las entidades financieras foráneas, "Foreign Financial Institutions" (FFI) que mantienen intermediación con contribuyentes estadounidenses» (Zavaleta \& Speer, 2012, p. 7). De este modo, la legislación norteamericana pretende valerse de las entidades financieras internacionales para perseguir el cumplimiento tributario de los ciudadanos norteamericanos que no residan en los Estados Unidos mediante incentivos tributarios a las entidades financieras que suscriban el convenio para reportar la información de los contribuyentes norteamericanos.

Esta clase de prerrogativas que tiene el sistema financiero americano y su influencia en el resto del mundo crean un escenario del que también

3 Véanse algunas de las principales normas vinculadas a la prevención vigentes en el Perú: Resolución SBS 2660-2015, sobre el reglamento de gestión de riesgo de lavado de activos y financiamiento del terrorismo; decreto supremo 018-2006-JUS, acerca de la creación de la Unidad de Inteligencia Financiera del Perú; decreto legislativo 1104, sobre la regulación penal sobre la pérdida de dominio; y decreto legislativo 1106, acerca de la regulación penal contra el lavado de activos.

4 El G-20 está conformado hoy por Alemania, Canadá, Estados Unidos, Francia, Italia, Japón y Reino Unido (G-7), Rusia (G-8) y once países recientemente industrializados del mundo y la Unión Europea como bloque económico.

5 Aprobada el 18 de marzo de 2010 por el Congreso de los Estados Unidos como parte de la ley de incentivos a la contratación para restaurar el empleo (Hire Act). 
participan los estándares de prevención de lavado de activos al exigirse a los bancos corresponsales y contrapartes que demuestren el debido cumplimiento de sus políticas de riesgo y procedimientos mediante, por ejemplo, el envío de un cuestionario de cumplimiento ${ }^{6}$.

\section{II.1. Relación entre los bancos y el lavado de activos}

Los bancos en nuestro contexto actual deben plantearse por qué los lavadores ingresan sus activos ilícitos a las empresas bancarias. La respuesta que nosotros planteamos es que el dulce no es la tasa de interés que ofrecen los bancos — al final, desde un punto de vista práctico, los lavadores generan para sí una mayor rentabilidad, minan la economía formal y los beneficios que la misma genera- sino, sobre todo, la apariencia de legalidad que les brinda la empresa. Esto es importante porque necesita demostrar frente al tercero - la comunidad en su conjunto- que es solvente, honesto y que tiene respaldo de la procedencia legal de su dinero.

La apariencia de legalidad es la finalidad última del lavado de activos cuando se ingresa los recursos ilícitos en el sistema financiero. Este elemento está recogido en las diversas definiciones de lavado de activos. Por ejemplo, en la Convención de las Naciones Unidas contra el Tráfico Ilícito de Estupefacientes y Sustancias Sicotrópicas que define el lavado de activos como «la conversión o la transferencia de bienes a sabiendas de que tales bienes proceden de alguno o algunos de los delitos tipificados de conformidad con el inciso a) del presente párrafo, o de un acto de participación en tal delito o delitos, con objeto de ocultar o encubrir el origen ilícito de los bienes o de ayudar a cualquier persona que participe en la comisión de tal delito o delitos a eludir las consecuencias jurídicas de sus acciones» (artículo 3, bi, p. 309).

En este contexto, las empresas bancarias son la vía más rápida para transferir fondos de un lugar a otro del mundo sin dejar rastro que pueda ser detectado, pues a nivel internacional se goza, ya sea de forma total o relativa, de la reserva bancaria ${ }^{7}$, lo cual protege de una u otra forma al lavador. Esta es la razón por la cual hoy los paraísos financieros ${ }^{8}$

6 Se trata de un conjunto de preguntas básicas formuladas por escrito (constituye una declaración jurada) con el propósito de acreditar que se cuente con ciertos mecanismos de control que brinden algún grado de efectividad en la prevención del lavado de activos. Lo cual significaría que de no contar con dichos mecanismos de control, el riesgo de la empresa bancaria se incrementa por incumplimientos.

7 El artículo 87 de la Constitución Política del Perú (1993) establece que «El Estado fomenta y garantiza el ahorro" y que, sobre la base del mandato constitucional, «la ley establece las obligaciones y los límites de las empresas que reciben ahorros del público, así como el modo y los alcances de dichas garantías». De esta forma, la ley 26702, en el artículo 140, regula el alcance de la prohibición a las empresas del sistema financiero, como a sus trabajadores y directores, de brindar información sobre las operaciones pasivas de sus clientes a menos que medie autorización de estos o sea requerido por autoridad competente.

8 Entre los principales paraísos financieros podemos mencionar los siguientes: en el Caribe se consideran islas Caimán, Vírgenes, Anguila, Antigua, San Vicente, Aruba y Antillas; en el continente

NI DEJAR HACER NI

DEJAR PASAR: EL

COMPROMISO DE

LAS INSTITUCIONES

BANCARIAS

PERUANAS FRENTE

AL LAVADO

DE ACTIVOS A

TRAVÉS DE LA

IMPLEMENTACIÓN

DE UNA

METODOLOGÍA

POR RIESGO

DON'T LET IT

HAPPEN NOR

LET IT GO:THE

COMMITMENT

OF PERUVIAN

BANKING

INSTITUTIONS

AGAINST MONEY

LAUNDERING

THROUGHTHE

IMPLEMENTATION

OF AN AML RISK

ASSESSMENT

METHODOLOGY 
son cuestionados, en la medida en que ocultan a los terceros que han obtenido sus recursos de forma ilegal al mantener en el anonimato a los propietarios de acciones de empresas domiciliadas en dichos paraísos financieros o fiscales, impidiendo determinar la procedencia u origen de sus recursos.

\section{II.2. El rol de los bancos frente al lavado de activos}

Las empresas bancarias saben hoy en día que hay una serie de políticas y normas a nivel internacional y nacional en los países donde operan que las convierten en «sujeto obligado» respecto al tema de prevención contra el lavado de activos 9 . Entonces nos volvemos a preguntar, ies únicamente por la norma que se lleva a cabo una u otra acción con respecto a la prevención del lavado de activos?

La respuesta indefectiblemente es no, la empresa bancaria lo hace también porque es socialmente responsable. Un ejemplo de esto es que la sociedad civil de algunos países, en especial de América Latina, ha encontrado una mejor respuesta por parte de las empresas privadas frente a las deficiencias del Estado al brindar apoyo a la comunidad donde operan. Esta respuesta está vinculada a las políticas de buen gobierno corporativo y responsabilidad social, donde no solo entran a tallar conceptos de transparencia y rendición de cuentas, sino elementos de «dirección, gestión y cumplimiento de objetivos medibles dentro de cada organización» (Haza, 2010, p. 328).

El gobierno interno de una empresa dirigido por personas que forman parte del directorio y las cúpulas gerenciales de primera y segunda línea son los responsables de estructurar la cultura organizacional a través de pautas de conducta en los negocios. Estas pautas consisten en elementos de integridad que fomentan desde prácticas éticas sobre cómo vender un producto financiero y cómo interpretar la reserva bancaria protegiendo la información de un cliente hasta el trato equitativo entre el personal de la organización y entre proveedores de productos o servicios (Haza, 2010, p. 328).

Es así que, primero se buscará generar conciencia sobre la gobernabilidad corporativa, luego se procederá a definir normas y principios cuyo cumplimiento posteriormente será objeto de seguimiento, se realizarán capacitaciones al personal en cada uno de sus roles y responsabilidades; y, finalmente, la empresa como un ente deberá tomar conciencia de su

asiático, Hong Kong, Singapur y Macao; en la zona del océano Índico, Isla Mauricio; en la zona del océano Pacífico, las islas Marshall, Nauru, Vanuatu, Samoa Occidental, Cook, Niue o Savage; en Europa, Isla de Man, Suiza, Luxemburgo, Dublín, Liechtenstein, Malta, Gibraltar, Andorra, Mónaco y Chipre.

9 Mediante la ley 27693 y su modificatoria, ley 28306, se estableció a las empresas bancarias, entre otros, como sujetos obligados a informar a la UIF-Perú acerca de operaciones sospechosas u operaciones de acuerdo con el monto que se fije vía reglamento. 
gobernabilidad como una parte normal y útil del negocio (Flores Konja \& Rozas Flores, 2008, p. 11).

Asimismo, la cultura organizacional también se fomenta estableciendo procedimientos de acción para temas que pueden afectar a la empresa bancaria como, por ejemplo, los intentos de financiación a grupos terroristas, aparición de riesgos legales, entre otros. Estos hechos pueden prevenirse mediante controles adecuados para ejecutar actividades con eficiencia, pudiendo ser de índole normativo o de reputación (Haza, 2010, p. 328). En ese sentido, «se crean las estructuras y procesos para la adecuada dirección y control de las empresas, que contribuyen a la generación de valor y a su desarrollo sostenible al mejorar su performance y su acceso a las fuentes de capital» (Claessens \& Yurtoglu, 2012, p. 33).

A pesar de ello, se debe prever que no es posible que los planes de acción instaurados para resolver problemas del quehacer diario respondan solucionando todos los escenarios. La comunicación entre todos los niveles gerenciales de las distintas unidades de la organización es otro factor necesario (Haza, 2010, pp. 328-329). Varias empresas bancarias han normado y clasificado en sus documentos internos una lista de «negocios de alto riesgo», compuesta por empresas con actividades económicas de legalidad cuestionable, que pueden afectar la reputación del banco o de cualquier empresa que forma parte del mismo grupo económico; empresas a las que no se les prestaría ningún tipo de crédito. Entre ellas podemos mencionar servicios financieros no regulados, juegos de azar, pornografía, sex shops, casinos no autorizados, agencias de viajes, comerciantes de joyas, gemas y piedras preciosas, personas políticamente expuestas, personas naturales o jurídicas a las que les hubieren levantado el secreto bancario, clientes ubicados en paraísos fiscales o financieros, etcétera (Haza, 2010, pp. 328-329).

\section{LOS BANCOS Y SU COMPROMISO EN EL SISTEMA DE PREVENCIÓN DE LAVADO DE ACTIVOS}

El lavado de activos en el caso del Perú es un problema que se ha ido agudizando en los últimos años, ya que se ha incrementado notablemente la cantidad de fondos provenientes de actividades ilícitas ingresados al sistema financiero. Esto, a todas luces, es un problema tanto económico como social. Es un problema económico porque el dinero proveniente de las actividades ilícitas es capaz de alterar el mercado y el sistema financiero al no funcionar bajo las reglas económicas comunes. Esto último se debe a que su objetivo no es realmente buscar ganancias legales con eficiencia, sino que son solo una fachada, por lo que pueden desestabilizar el sistema al mover grandes sumas de dinero de forma imprevisible. Asimismo, es un problema social porque el dinero obtenido de actividades ilícitas ingresa al sistema y, al obtener apariencia

NI DEJAR HACER NI DEJAR PASAR: EL COMPROMISO DE LAS INSTITUCIONES BANCARIAS PERUANAS FRENTE AL LAVADO

DE ACTIVOS A

TRAVÉS DE LA IMPLEMENTACIÓN

DE UNA

METOdOLOGÍA POR RIESGO

DON'T LET IT HAPPEN NOR

LET IT GO:THE COMMITMENT OF PERUVIAN

BANKING

INSTITUTIONS AGAINST MONEY LAUNDERING THROUGHTHE IMPLEMENTATION OF AN AML RISK ASSESSMENT METHODOLOGY 
de legalidad, sirve a su vez para financiar la comisión de nuevos delitos cuyas ganancias vuelven a ingresar al sistema, alimentando así un círculo vicioso. Así, para Edgardo Varela y Ángel Venini, «las consecuencias inmediatas del lavado de dinero serán entonces la erosión de las instituciones financieras, modificación de la demanda de dinero en efectivo, desestabilización de las tasas de interés y el tipo de cambio, aumento de la inflación de los países donde actúan preferentemente los delincuentes globales y que, en último término, afectan la estabilidad financiera de los países más vulnerables» (Varela \& Venini, 2007, p. 78).

En este mismo sentido, de acuerdo con Inés López Valera, las implicancias negativas para el país y las empresas pueden ser 1) la competencia desleal porque los fondos clandestinos subvencionan productos con precios fuera de los márgenes de lo que ofrece el mercado, 2) inestabilidad del mercado por el desvío de fondos de inversiones legítimas a inversiones deficientes, dañando los índices de crecimiento económico al no seguir el patrón de rentabilidad que buscan los negocios legales, 3) pérdida de ingresos tributarios, y finalmente, 4) alto riesgo reputacional por la pérdida de confianza en los mercados, ocasionado por los delitos financieros y la especulación bursátil (López Valera, 2014).

Entonces, ipor qué debería interesarles a los bancos implementar medidas de lavado de activos para reducir al mínimo los actos de corrupción en su entidad? Los bancos, al ser empresas, dependen en gran medida de la confianza del cliente para tener éxito y, en palabras de Villegas, «es útil recordar que la confianza es el principal activo de un banco que se gana lentamente y se pierde muy rápidamente» $(1999$, p. 8).

El riesgo se presenta al poderse mellar en gran medida la reputación de un banco, desprestigiándolo al punto de generar una percepción negativa no solo en sus clientes, sino también en sus propios accionistas, potenciales inversionistas y otros agentes de mercado. Esta percepción negativa dificultaría la captación de recursos para poder a su vez colocarlos, es decir, dificultaría llevar a cabo la actividad principal del banco. Entonces, entre las razones por las que los bancos deben preocuparse por el riesgo de lavado de activos, está el hecho de que son las entidades más representativas del sistema financiero. Esto significa que, si la ciudadanía pierde la confianza en los bancos, sería mucho menos probable que pueda confiar en otra empresa del sistema financiero como una financiera, una caja municipal de ahorro y crédito o una Entidad de Desarrollo para la Pequeña y Microempresa (Edpyme), peligrando de esta manera la subsistencia del sistema en su conjunto.

Un ejemplo de aplicación del sistema de prevención de lavado de activos en el mundo es el acontecido el 09 de agosto de 2016. En dicha fecha se anunció el cierre de la filial italiana del Banco AS PrivatBank al detectarse graves violaciones de la normativa contra el lavado de 
capitales y presentar riesgo de reincidencia, pese a que el AS PrivatBank, subsidiaria de PrivatBank, era una de las diez entidades financieras más importantes de Europa del Este ${ }^{10}$ (El Confidencial, 09 de agosto de 2016).

Conforme a lo expuesto, lo que venimos observando en el caso peruano es un marco regulatorio que responde a los estándares de los organismos internacionales. Sin embargo, el propio Estado, a través de sus organismos de control y supervisión, no ha sido lo suficientemente capaz de superar sus propias debilidades estructurales a lo largo de los años. Una de estas debilidades consistente en no haber podido elaborar una metodología de identificación y evaluación de riesgo en LA/TF para las empresas de operaciones múltiples del sistema financiero nacional. Sin embargo, el Estado sí tiene la capacidad normativa por el ius imperio de disponer que sean los propios bancos los que elaboren, en calidad de sujeto obligado en el tema de prevención de LA/FT una serie de herramientas, entre ellas una metodología de identificación y evaluación por riesgo en prevención de lavado de activos.

Es importante, sin embargo, considerar ciertas resoluciones de la Superintendencia de Mercado de Valores (SMV) y de la SBS (Resolución CONASEV 033-2011-EF/94.01.1, Resolución SMV 007-2013. SMV/01, modificatoria de la resolución previa, y Resolución SBS 2660 2015). A pesar de que estos documento no son textos normativos que contengan el desarrollo de una metodología por riesgo en prevención de LA/FT dan luces de lo que pretende el Estado en su búsqueda.

La situación descrita ha obligado a las empresas bancarias a desarrollar un modelo de gestión integral de riesgos que involucre otros riesgos como el riesgo crediticio, el riesgo operativo, el riesgo de mercado, el riesgo de reputación, y el riesgo legal antes de aplicar una metodología por riesgo en prevención de lavado de activos. Con el fin de administrar los distintos riesgos, hoy las empresas bancarias han propuesto tres líneas de defensa: línea de negocio, unidad de riesgo y auditoría interna.

10 Entre otros casos de sanciones por faltas al sistema de prevención de lavado de activos aplicado a las empresas bancarias, podemos mencionar las investigaciones que se les sigue a los ex colaboradores del presidente Hugo Chávez en Venezuela (Perú21, 17 de marzo de 2015), el caso de la operación «lava jato» (ADN Paraguayo, 22 de junio de 2016) y el caso del Bank of Tokyo. Este último fue reseñado por Selina Román en el sitio web Prevención de Lavado de Dinero (http://www. lavadodedinero.com/) el 21 de diciembre de 2006: «La Corporación Federal de Seguros de Depósitos de los EE.UU. (por sus siglas en inglés FDIC) y el Departamento Bancario del Estado de Nueva York amonestaron al Bank of Tokyo - Mitsubishi UFJ Trust Company el lunes por prácticas "inseguras e ineficientes" en su sucursal de Nueva York. En una orden conjunta de cesar y desistir y un acuerdo escrito separado de 10 páginas, los reguladores estatales y federales citaron al cuarto banco más grande del mundo por un programa antilavado de dinero deficiente que omitió capacitar a los empleados acerca de las obligaciones de la Ley Secreto Bancario (LSB), incluyendo la identificación de figuras políticas y sus asociados - a menudo conocidas como personas expuestas políticamente o PEPs. El banco japonés ha tenido su porción de clientes de alto riesgo, incluyendo al exilado presidente peruano Alberto K. Fujimori. El año pasado, las autoridades peruanas descubrieron que Fujimori, antes de asumir su cargo en 1990, instruyó a un asociado político para que abriera una cuenta en una sucursal japonesa del Bank of Tokyo a nombre de la embajada peruana. La propiedad de la cuenta, supuestamente creada para aceptar donaciones para los niños pobres del Perú, fue posteriormente transferida a Fujimori».

NI DEJAR HACER NI DEJAR PASAR: EL COMPROMISO DE LAS INSTITUCIONES BANCARIAS PERUANAS FRENTE AL LAVADO

DE ACTIVOS A

TRAVÉS DE LA IMPLEMENTACIÓN DE UNA METOdOLOGÍA POR RIESGO

DON'T LET IT HAPPEN NOR

LET IT GO:THE COMMITMENT OF PERUVIAN

BANKING

INSTITUTIONS AGAINST MONEY LAUNDERING THROUGHTHE IMPLEMENTATION OF AN AML RISK ASSESSMENT METHODOLOGY 
La línea de negocio (primera línea) es la dueña del riesgo. La línea o gerencia o vicepresidencia de riesgo (segunda línea) es la supervisora y proveedora de objetivos a la primera línea. Asimismo, es la que realiza el seguimiento y control de los diferentes riesgos que toma o asume el banco como empresa de operaciones múltiples. Finalmente, auditoría interna (tercera línea) constata que los objetivos de control sean logrados por la primera y segunda línea de defensa.

Tabla 1

\begin{tabular}{|c|c|c|}
\hline $\begin{array}{c}\text { Primera línea de } \\
\text { defensa }\end{array}$ & $\begin{array}{l}\text { Segunda línea de } \\
\text { defensa }\end{array}$ & $\begin{array}{l}\text { Tercera línea de } \\
\text { defensa }\end{array}$ \\
\hline Líneas de negocios & Departamento de riesgo & Auditoría interna \\
\hline $\begin{array}{l}\text { - Dueña del riesgo asocia- } \\
\text { do al objeto social de la } \\
\text { empresa de operaciones } \\
\text { múltiples. } \\
\text { - Aplica el criterio del ne- } \\
\text { gocio, evalúa el riesgo de } \\
\text { su actividad. } \\
\text { - Se desenvuelve dentro } \\
\text { del apetito del riesgo } \\
\text { contenido en políticas de } \\
\text { gestión por riesgo de la } \\
\text { empresa. }\end{array}$ & $\begin{array}{l}\text { - Responsable del desarro- } \\
\text { llo e implementación de } \\
\text { las políticas de riesgo. } \\
\text { - Brinda asesoramiento, } \\
\text { capacitación y herra- } \\
\text { mientas para apoyar el } \\
\text { cumplimiento de la polí- } \\
\text { tica. }\end{array}$ & $\begin{array}{l}\text { - Realiza la constatación, } \\
\text { el control del cumpli- } \\
\text { miento de la política. } \\
\text { - Reporta las observacio- } \\
\text { nes al Directorio como } \\
\text { oportunidades de mejo- } \\
\text { ras producto de su enfo- } \\
\text { que del gobierno corpo- } \\
\text { rativo. }\end{array}$ \\
\hline
\end{tabular}

En el caso de una metodología de identificación por riesgo, su finalidad es llegar a identificar, comprender, entender y valorar en calidad de insumos: 1) la estadística nacional de lavado de activos, 2) definir qué comprende el riesgo de lavado de activos, 3) analizar los factores del riesgo de lavado de activos, 4) determinar su riesgo inherente, 5) determinar su propio umbral de gestión por riesgo, 6) la aplicación de controles sobre aquel denominado riesgo de lavado de activos para llegar finalmente al monitoreo de ese riesgo llamado LA/FT. Todo ello se debe ver reflejado previamente en una matriz de valorización por riesgo.

A continuación y tomando en cuenta lo expuesto, pasaremos a revisar la estadística nacional de reporte de operaciones sospechosas por lavado de activos.

\section{III.1. Estadística nacional de reporte de operaciones sospechosas por lavado de activos en el Perú}

La debilidad estructural del país se refleja en las estadísticas de la UIF-Perú. Las cifras demuestran la cantidad de dinero que estaría siendo lavado a través del sistema financiero: 838 millones de dólares 
americanos entre abril del año 2016 y marzo del año 2017 (SBS, 2017, p. 8). En los últimos 12 meses, del total de reportes de operaciones sospechosas (ROS) recibidos por la UIF-Perú, el 33\% corresponde a reportes enviados por los bancos. El porcentaje de reportes enviados por los bancos es superado en $1 \%$ por las notarías, como se puede apreciar en el siguiente gráfico:

\section{Gráfico 1}

Reporte de operaciones sospechosas - Participación por tipo de sujeto obligado - últimos doce meses a marzo de 2017

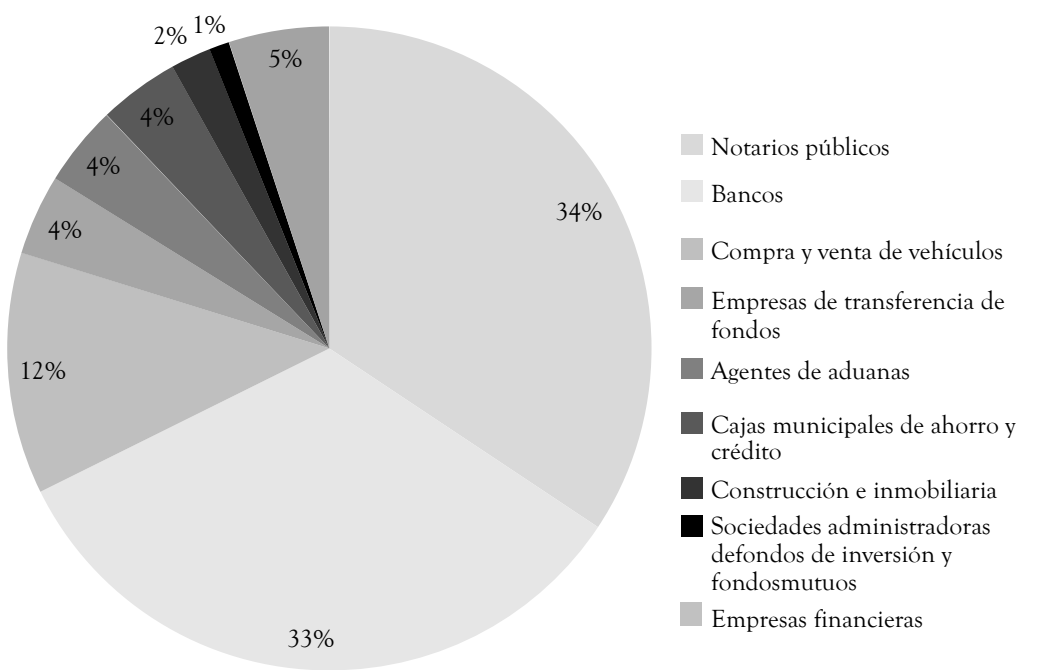

Fuente: SBS, 2017, p. 5.

Podemos apreciar que, dado el reciente cambio legislativo mediante el decreto legislativo 1249, los notarios públicos han igualado y posteriormente sobrepasado a los bancos como los sujetos obligados que más reportan a la UIF-Perú. Pese a ello, el sistema financiero aún se configura como el mejor escenario para «servir como instrumento de las organizaciones criminales para su recapitalización, así como para el aseguramiento de sus capitales» (Paucas, 2013, p. 29). La gran cantidad de dinero canalizado y la complejidad de los productos financieros, sumado a la profesionalización del delito al contar las organizaciones criminales con equipos de profesionales y asesores legales y financieros, materializan la premisa de que los bancos son por excelencia los intermediarios financieros preferidos para captar fondos de origen ilícito. Dicha afirmación se puede observar en el gráfico 2, que corresponde a las estadísticas históricas desde el año 2007 hasta 2016. El gráfico muestra que los bancos ocupan el primer lugar con un 38\% en cuanto a emisiones de ROS. 

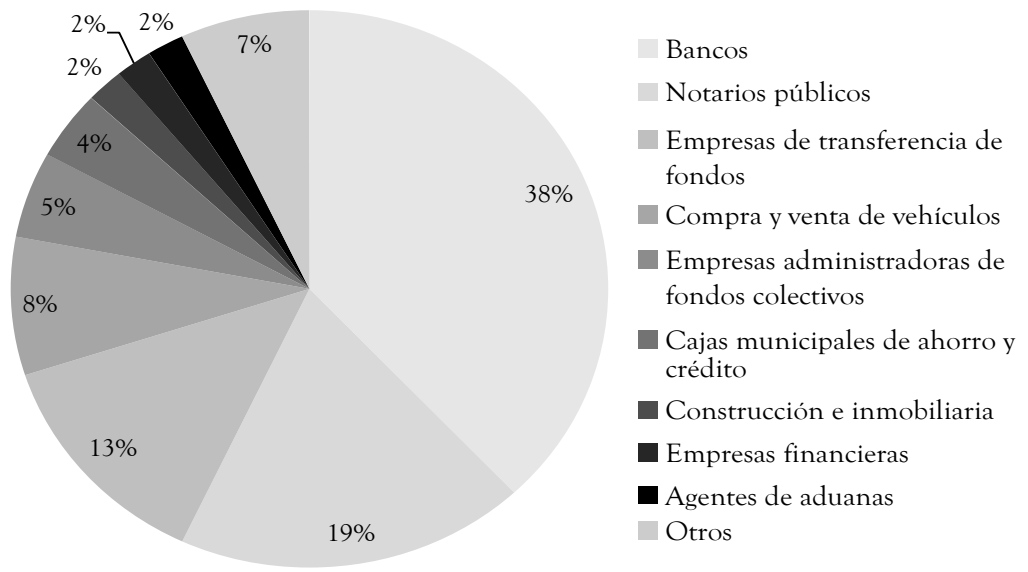

Fuente: SBS, 2017, p. 4.

En contraposición a lo mencionado, llama la atención en ambos cuadros que, a pesar de que las cajas municipales tienen una importante participación a nivel de mercado respecto al sistema financiero, solo reportan el 5\% de los ROS. Esto podría ser un indicador de oportunidad de mejora en la implementación de un sistema de prevención de lavado de activos.

Asimismo, podemos observar que se repite el patrón en la participación de los sujetos obligados respecto del ROS. Esto indicaría que, desde el año 2007, no habría cambiado mucho la situación de los sujetos obligados respecto a la mejora en la implementación de sus sistemas de prevención de lavado de activos, ni en su rol como las empresas del sistema financiero ni en su uso por parte de los lavadores de activos en general.

\section{III.2. La corrupción en el contexto peruano \\ III.2.1. Corrupción como referente del lavado de activos}

Desde abril del año 2016 hasta marzo de 2017, el monto correspondiente a activos provenientes de delitos de corrupción reportados ascendería a 446 millones de dólares americanos, ocupando el primer lugar como el delito más vinculado a casos de lavado de activos, desplazando ampliamente a los delitos de tráfico ilícito de drogas y minería ilegal en el último año. Si bien a nivel acumulado desde enero de 2007 los delitos contra la administración pública ocuparon el tercer lugar, actualmente estamos frente a un nuevo escenario que demuestra la gravedad de los 
niveles de corrupción en nuestro país, como puede apreciarse en la tabla 2 .

Tabla 2

Monto involucrado en los Informes financieros por delito precedente enero de 2007 a marzo de 2017

\begin{tabular}{|c|c|c|c|c|}
\hline \multirow[t]{2}{*}{ Posible delito vinculado } & \multicolumn{2}{|c|}{$\begin{array}{l}\text { Acumulado: enero } \\
\text { de } 2007 \text { a marzo de } \\
2017 \\
\end{array}$} & \multicolumn{2}{|c|}{$\begin{array}{l}\text { Doce meses: abril de } \\
2006 \text { a marzo de } 2017\end{array}$} \\
\hline & $\begin{array}{l}\mathrm{N}^{\circ} \text { de } \\
\mathrm{IIF}\end{array}$ & $\begin{array}{c}\text { Total de } \\
\text { millones } \\
\text { US\$ }\end{array}$ & $\mathrm{N}^{\circ}$ de IIF & $\begin{array}{l}\text { Total de } \\
\text { millones } \\
\text { US\$ }\end{array}$ \\
\hline Tráfico ilícito de drogas & 284 & 5395 & 3 & 19 \\
\hline Minería ilegal & 42 & 4477 & 10 & 98 \\
\hline $\begin{array}{l}\text { Delitos contra la administración pú- } \\
\text { blica (corrupción de funcionarios y } \\
\text { enriquecimiento ilícito) }\end{array}$ & 151 & 1362 & 19 & 446 \\
\hline $\begin{array}{l}\text { Defraudación de rentas de aduanas / } \\
\text { contrabando }\end{array}$ & 40 & 449 & 5 & 147 \\
\hline $\begin{array}{l}\text { Delitos contra el orden financiero y } \\
\text { monetario }\end{array}$ & 10 & 419 & 2 & 11 \\
\hline Defraudación tributaria & 53 & 474 & 5 & 68 \\
\hline Estafa / fraude & 21 & 162 & - & - \\
\hline Delitos contra el patrimonio & 10 & 54 & 3 & 28 \\
\hline Proxenetismo & 10 & 27 & - & - \\
\hline Financiamiento del terrorismo & 20 & 8 & 2 & 1 \\
\hline Trata de personas & 5 & 3 & - & - \\
\hline Otros & 222 & 956 & 11 & 20 \\
\hline Total & 868 & 13786 & 60 & 838 \\
\hline
\end{tabular}

NI DEJAR HACER NI DEJAR PASAR: EL COMPROMISO DE LAS INSTITUCIONES BANCARIAS PERUANAS FRENTE AL LAVADO

DE ACTIVOS A

TRAVÉS DE LA

IMPLEMENTACIÓN

DE UNA

METODOLOGÍA POR RIESGO

DON'T LET IT

HAPPEN NOR

LET IT GO: THE

COMMITMENT

OF PERUVIAN

BANKING

INSTITUTIONS

AGAINST MONEY

LAUNDERING

THROUGHTHE

IMPLEMENTATION

OF AN AML RISK

ASSESSMENT

METHODOLOGY

Fuente: SBS, 2017, p. 8.

Dentro de los delitos de corrupción, una de las tipologías más usadas son las licitaciones públicas, mediante las cuales un funcionario público favorece el otorgamiento de la buena pro a una empresa determinada y luego de que el Estado le paga a la empresa, la empresa, a través de sus subsidiarias, le «paga» al funcionario público un monto correspondiente a «servicios de consultoría», por ejemplo. Estos servicios, sin embargo, son una operación de fachada para entregarle una comisión al funcionario público corrupto (véase el gráfico 3). 


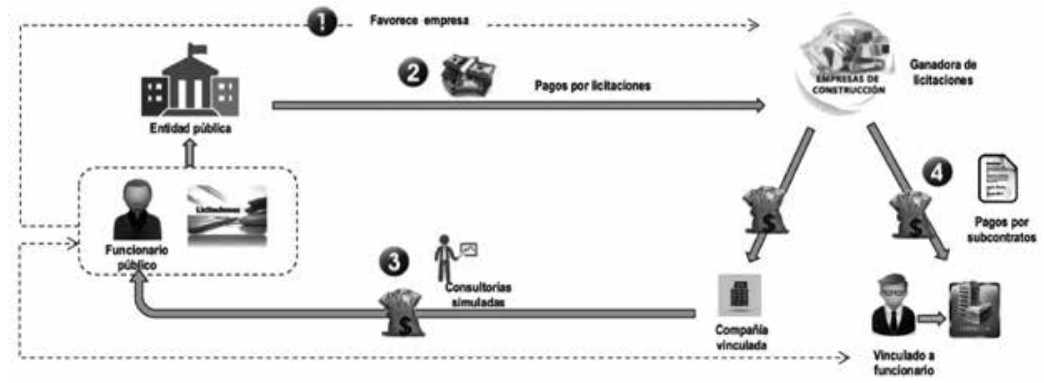

Fuente: Diagrama general disponible en el Portal UIF-Perú, en la página de Tipologías Nacionales (http://www.sbs. gob.pe/prevencion-de-lavado-activos/publicaciones/tipologias-de-laft/tipologias-nacionales)

Todo lo expresado se evidencia en el contexto peruano en el incremento de las actividades de corrupción pública, tal como afirma la Evaluación Nacional de Riesgos. En esta evaluación se menciona que la corrupción tiene una mayor trascendencia económica, pues involucra millones de dólares. Esto, sumado a la nula respuesta ágil en su persecución y punición, incentiva la comisión de los delitos contra la administración pública, haciendo de la tolerancia y permisibilidad a la corrupción un riesgo muy alto (SBS \& BID, 2016, p. 49).

\section{III.2.2. Percepción de la corrupción por la ciudadanía}

Por otro lado, respecto a la percepción de la ciudadanía sobre la corrupción en el país, se acredita que la tolerancia de la población es muy elevada. La encuesta nacional de Pulso Perú muestra cifras sorprendentes: un 49\%, siete puntos más que en octubre de 2015, está de acuerdo con la frase «la corrupción es algo propio de la cultura peruana» (véase gráfico 4).

Los resultados según el grupo socioeconómico reportan que en el segmento D esta cifra aumenta hasta 52\% y, en relación con el ámbito geográfico, en la zona norte aumenta a 56.3\%. En Lima, un 50.5\% de los ciudadanos está de acuerdo (Gestión, 11 de octubre de 2016).

Más grave, sin embargo, resulta que el $45 \%$ reconozca que es muy tolerante a los actos de corrupción en política. El año anterior, solo el 19\% reconocía ser muy tolerante a los actos de corrupción. En este mismo punto, en 2015, el 31\% afirmaba que los peruanos son poco tolerantes ante este problema; ese grupo se redujo en 2016 a solo $15 \%$. El segmento D admitió mucha tolerancia con la corrupción (50.9\%), seguido del segmento $\mathrm{E}$ (47.3\%). En el caso de las regiones, la percepción de corrupción la lideran el norte (53.6\%) y el oriente (44.9\%) del país. En Lima, la tolerancia con la corrupción alcanza el $42.8 \%$ y en el segmento A/B, al 43.3\% (Gestión, 11 de octubre de 2016). 
Gráfico 4. Razones que explican la corrupción (1)

«La corrupción es algo propio de

la cultura peruaba»

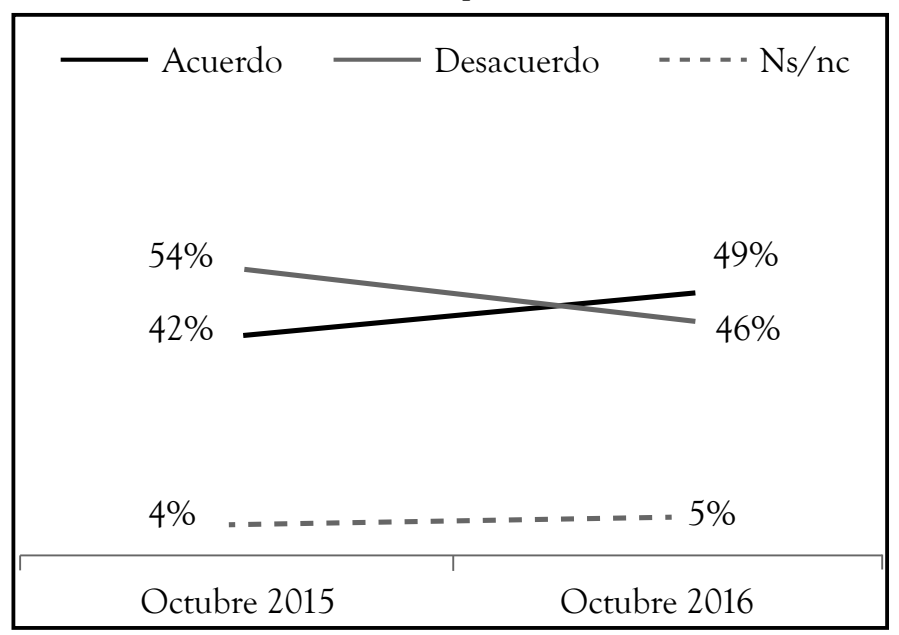

Total $100 \%$

Base: 1203 entrevistas

Fuente: Encuesta Pulso Perú: Mapa de la corrupción en el país (11 de octubre de 2016, imagen 14) ${ }^{11}$.

Esto parece corresponderse con el hecho de que el 63\% de los ciudadanos — cuatro puntos más que el año previo, 2015 — afirme que «a los peruanos, en el fondo, la corrupción les da lo mismo» (Gestión, 11 de octubre de 2016; véase gráfico 5).
NI DEJAR HACER NI

DEJAR PASAR: EL

COMPROMISO DE

LAS INSTITUCIONES

BANCARIAS

PERUANAS FRENTE

AL LAVADO

DE ACTIVOS A

TRAVÉS DE LA

IMPLEMENTACIÓN

DE UNA

METODOLOGÍA

POR RIESGO

\section{DON'T LET IT}

HAPPEN NOR

LET IT GO: THE

COMMITMENT

OF PERUVIAN

BANKING

INSTITUTIONS

AGAINST MONEY

LAUNDERING

THROUGHTHE

IMPLEMENTATION

OF AN AML RISK

ASSESSMENT

METHODOLOGY

11 Ficha técnica. Encuestadora: Datum Internacional SA con N. ${ }^{\circ}$ de registro: 0002-REE/JNE. Clientes: Prensa Popular. Muestra: 1203 encuestas. Cobertura: nivel nacional. Técnica: encuesta personal. Margen de error: $+/-2.8 \%$ con un nivel de confianza de $95 \%$. Fecha de campo: 30 de septiembre al 04 de octubre. 


\section{Gráfico 5. Razones que explican la corrupción (2)}

«A los peruanos, en el fondo, la corrupción

les da lo mismo"

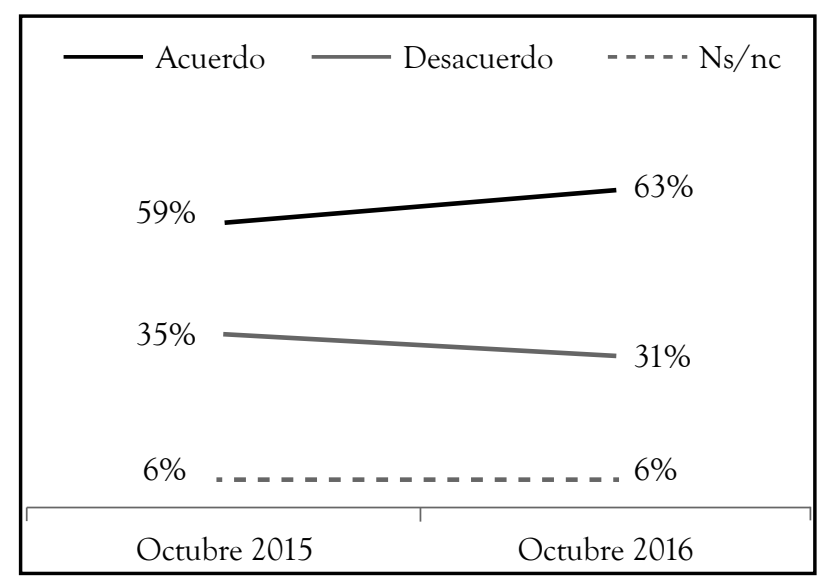

Total $100 \%$

Base: 1203 entrevistas

Fuente: Encuesta Pulso Perú: Mapa de la corrupción en el país (11 de octubre de 2016, imagen 15)

Lo indicado en párrafos anteriores da la impresión de que los peruanos somos por naturaleza corruptos, lo cual es falso. Lo que demuestra la cifra según la cual el 49\% piensa que la corrupción es algo normal o cotidiano y que forma parte del quehacer del país es precisamente lo que se requiere cambiar, utilizando todas las herramientas posibles. Para ello, nuestra contribución con la lucha anti-lavado busca ser un eslabón más de la cadena de acciones que el Estado y otros sujetos privados tienen que implementar, mediante el adecuado cumplimiento de la normativa de prevención de lavado de activos que exige a las instituciones bancarias la aplicación de controles internos. Los bancos aplican estas políticas con el fin de obtener la suficiente cantidad de información de sus clientes que les permita descubrir elementos corruptos cuando estos intenten adquirir un producto bancario.

A continuación, planteamos los criterios mínimos que debe considerar una metodología por riesgo en LA/FT. Dicha metodología es producto del intercambio de información académica y experiencia profesional entre los distintos Oficiales de Cumplimiento en Prevención de Lavado de Activos de algunas de las empresas que forman parte del sistema bancario nacional. Nuestra propuesta intenta reflejar los resultados de este proceso de intercambio. 


\section{NUESTRA PROPUESTA: UNA METODOLOGÍA DE IDENTIFICACIÓN Y EVALUACIÓN POR RIESGOS EN PREVENCIÓN DE LAVADO DE ACTIVOS}

De acuerdo con la guía del enfoque basado en riesgos para el sector bancario del Grupo de Acción Financiera Internacional (GAFI) ${ }^{12}$, el Enfoque Basado en Riesgos (EBR) «significa que los países, autoridades competentes e instituciones financieras, deben identificar, evaluar y entender los riesgos en LA/FT a los que están expuestos y adoptar las medidas adecuadas para mitigar de manera efectiva dichos riesgos» ${ }^{13}$ (GAFI, 2014, p. 8).

La metodología de identificación y evaluación por riesgo permite identificar y analizar los riesgos que son diferentes en cada país, estableciendo una base sensible sobre la que deben enfatizarse las medidas de prevención de lavado de activos. Esto quiere decir que las medidas de prevención se aplicarán de acuerdo con los riesgos presentes en cada jurisdicción, debiendo reforzarse en aquellos casos que sean más sensibles y pudiendo flexibilizarse en los demás. De este modo, los recursos pueden ser usados de forma eficiente, siendo invertidos donde más se necesitan.

Ahora bien, es importante resaltar que la metodología de identificación y evaluación por riesgo no solo se ve reflejada en las normas legales que adoptará cada país, sino también debe verse reflejada individualmente a nivel de cada entidad bancaria. Por ejemplo, cada país establecerá las normas mínimas que deberán ser aplicadas en la implementación del sistema de prevención de lavado de activos, pero también cada banco deberá tomar como base esas normas. Así, de acuerdo con los sectores donde opera y otros aspectos que le ayuden a identificar sus riesgos más sensibles, deberá adoptar sus propias políticas internas, las cuales tendrán que ir más allá de las establecidas como piso mínimo por la legislación nacional. Así, la guía del enfoque basado en el riesgo para el sector bancario del GAFI indica que «cuando los riesgos de LA/FT son mayores, los bancos siempre deberán aplicar la debida diligencia reforzada, incluso cuando las leyes o normas nacionales no indiquen

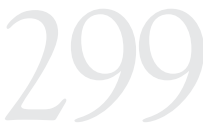

NI DEJAR HACER NI DEJAR PASAR: EL COMPROMISO DE LAS INSTITUCIONES BANCARIAS PERUANAS FRENTE AL LAVADO

DE ACTIVOS A TRAVÉS DE LA IMPLEMENTACIÓN DE UNA

METOdOLOGÍA POR RIESGO

DON'T LET IT HAPPEN NOR

LET IT GO: THE COMMITMENT OF PERUVIAN

BANKING

INSTITUTIONS AGAINST MONEY LAUNDERING THROUGHTHE IMPLEMENTATION OF AN AML RISK ASSESSMENT METHODOLOGY

12 «El Grupo de Acción Financiera Internacional (GAFI) es un organismo intergubernamental independiente que desarrolla y promueve políticas para proteger el sistema financiero mundial contra el lavado de activos, el financiamiento del terrorismo y el financiamiento de la proliferación de armas de destrucción masiva. Las Recomendaciones del GAFI son reconocidas por ser una guía a nivel mundial contra el lavado de activos (ALA) y el estándar internacional sobre la lucha contra el financiamiento del terrorismo (CFT)» (GAFI, 2014, p. 2).

13 La guía del enfoque basado en el riesgo para el sector bancario, elaborada por el GAFI en octubre de 2014 , se realizó con la finalidad de «[p]reparar los principios que deben ponerse en práctica en la aplicación de un enfoque basado en riesgo de ALA/CFT; colaborar con los países, las autoridades y los bancos para el diseño y puesta en práctica de un enfoque basado en riesgo de ALA/CFT al compartir ejemplos y directrices generales de las prácticas actuales; contribuir para una supervisión y puesta en marcha efectiva de las medidas nacionales de ALA/CFT, centrándose en los riesgos y en las medidas de mitigación; y sobre todo, fomentar el desarrollo de un entendimiento común en cuanto a lo que es el enfoque basado en riesgo de ALA/CFT y lo que implica» (GAFI, 2014, p. 6). 
de forma clara cómo mitigar estos riesgos mayores (ej.; mediante la variación del grado continuo de monitoreo reforzado)» (GAFI, 2014, p. 10).

Algo que es importante señalar es que el sistema de prevención de lavado de activos es de medios y no de resultados. Esto quiere decir que el sistema no garantiza que no se llevarán a cabo actividades ilegales, por lo que no se puede responsabilizar ni a la entidad ni a los funcionarios por la ocurrencia de un incidente como este. Lo que se tendrá que evaluar para hallar responsabilidad es si la entidad financiera ha incorporado todas las políticas y medidas necesarias para prevenir el riesgo de lavado de activos, es decir, si el banco y el Oficial de Cumplimiento ${ }^{14}$ han actuado con debida diligencia ${ }^{15}$.

Por ello, los bancos hoy plantean, como parte de su compromiso con constituirse en una primera línea de defensa preventiva, lograr obtener la mayor información posible durante el inicio de la relación comercial. Este medida, junto con la verificación correspondiente, les permita tener la certeza de saber con quién se contrata; sobre esta base se pueda determinar un puntaje o scoring para el cliente. Ello implica que, si con el tiempo el cliente hace algo distinto a sus actos habituales y supera su propia puntuación generada por el scoring, se procederá inmediatamente a una nueva evaluación de la relación comercial porque la misma varió al generar una señal de alerta en el tema de prevención.

\section{IV.1. Riesgo de lavado de activos}

Como podemos observar, el negocio de un intermediario financiero —en especial del banco- siempre es captar y prestar dinero. Sin embargo, hoy dichos actos jurídicos han llevado a los bancos a generar estratégicamente un sistema financiero seguro y confiable en cualquier país donde opere mediante la adopción de una metodología de identificación y evaluación del riesgo de lavado de activos. Esta metodología está dirigida a detectar e impedir el uso de sus productos, servicios o canales con finalidades ilegales, es decir, ser utilizado para operaciones de lavado, diferenciando

14 La Resolución SBS 2660-2015 establece, entre otras, las siguientes las responsabilidades y funciones del Oficial de Cumplimiento: «a) Proponer las estrategias de la empresa para prevenir y gestionar los riesgos de LA/FT. b) Vigilar la adecuada implementación y funcionamiento del sistema de prevención del LA/FT. c) Evaluar y verificar la aplicación de las políticas y procedimientos implementados en el sistema de prevención del LA/FT, según lo indicado en el Reglamento, incluyendo el registro de operaciones y la detección oportuna y reporte de operaciones sospechosas» (artículo 11).

15 La primera disposición complementaria final del decreto legislativo 1106 establece que: «Los sujetos obligados establecidos a través de la ley 27693 deberán reportar bajo responsabilidad de forma inmediata y suficiente a la Unidad de Inteligencia Financiera cualquier información relevante sobre manejo de activos o pasivos u otros recursos, cuya cuantía o características no guarden relación con la actividad económica de sus clientes, o sobre transacciones de sus usuarios que por su número, por las cantidades transadas o por las características particulares de las mismas, puedan conducir razonablemente a sospechar que se está utilizando a la entidad para transferir, manejar, aprovechar o invertir recursos provenientes de actividades delictivas o destinados a su financiación». 
el riesgo de lavado de activos de otros riesgos como el riesgo crediticio, el riesgo operativo o el riesgo del mercado ${ }^{16}$.

El regulador SBS define lo que debemos comprender por riesgos de LA/ FT: «posibilidad de que la empresa sea utilizada para fines de LA/FT. Esta definición excluye el riesgo de reputación y el operacional» (Resolución SBS 2660-2015, artículo 2, literal o). A primera vista, la definición no precisa suficientemente cómo comprender el riesgo de LA/FT, nos dice que se encuentran excluidos de plano el riesgo operativo y el de reputación. Adicionalmente, comprenderíamos otros tipos de riesgos como el mismo riesgo legal, el crediticio o el de mercado, que también se encontrarían excluidos.

El Diccionario de la Real Academia de la Lengua Española define riesgo como «función de la probabilidad de la ocurrencia de un suceso y de la cuantía del daño que puede provocar». Ahora, teniendo una definición más precisa y releyendo la definición aprobada por el regulador SBS, diríamos que el riesgo como tal requiere de indicadores directos que se encuentran en la esencia de lo que es un riesgo como la amenaza y la vulnerabilidad, que no son sinónimos sino componentes del denominado riesgo de lavado de activos.

La amenaza no es otra cosa que el hecho externo, la probabilidad, la advertencia o el presagio de una ocurrencia sobre la cual no tenemos control. Por amenaza externa entendemos lo siguiente: la existencia de flujos de fondos de origen ilícito en poder de organizaciones criminales; la voluntad del lavador de activos (defraudador tributario, narcotraficante, otros) de introducirlos en el circuito económico a través de empresas financieras propensas a ser utilizadas con el propósito de hacerlo parecer como dinero lícito; y el lavado de activos que rodea a algunos organismos del Estado, con lo que afecta la capacidad de respuesta tanto de autoridades como de operadores de justicia.

La vulnerabilidad no debe ser entendida como debilidad, sino como el grado de pérdida capaz de afectar al sujeto pasivo — entiéndase empresa bancaria- que se encuentra vinculado por la amenaza. Así, entendemos por debilidad o vulnerabilidad interna lo siguiente: medidas preventivas, estrategias, que se adoptan antes de que ocurra el evento indeseado (el acto mismo de lavado de activos) como la capacitación al personal, contar con políticas en la evaluación y diseño de productos o procesos;

16 Según el anexo glosario de la ley 26702, el riesgo de crédito es «el riesgo de que el deudor o la contraparte de un contrato financiero no cumplan con las condiciones del contrato"; el riesgo operativo es «el riesgo de sufrir pérdidas debido a la inadecuación o a fallos de los procesos, el personal y los sistemas internos o bien a causa de acontecimientos externos (excluye el riesgo estratégico y el de reputación)»; y el riesgo de mercado es «la probabilidad de tener pérdidas en posiciones dentro y fuera de la hoja del balance, derivadas de movimientos en los precios de mercado, incluyéndose a los instrumentos relacionados con tasas de interés, riesgo cambiario, cotización de las acciones, commodities, y otros".

NI DEJAR HACER NI DEJAR PASAR: EL COMPROMISO DE LAS INSTITUCIONES BANCARIAS PERUANAS FRENTE AL LAVADO

DE ACTIVOS A

TRAVÉS DE LA

IMPLEMENTACIÓN

DE UNA

METOdOLOGÍA

POR RIESGO

DON'T LET IT

HAPPEN NOR

LET IT GO:THE

COMMITMENT

OF PERUVIAN

BANKING

INSTITUTIONS

AGAINST MONEY

LAUNDERING

THROUGHTHE

IMPLEMENTATION

OF AN AML RISK

ASSESSMENT

METHODOLOGY 
medidas de control, cuando ha sido superada la medida de prevención, las medidas de control (como las señales de alerta básicas) se activan de forma automática, por ejemplo, el cliente se niega a brindar información sobre el origen de sus fondos; y la capacidad de respuesta, la actitud del personal involucrado para implementar mejoras en el diseño del sistema de prevención.

La relación de ambos indicadores nos dará por resultado el riesgo específico. Este es el grado de pérdida esperado por el sujeto obligado en LA/FT llamado banco. La pregunta que cae por su propio peso es saber si ambos indicadores (amenaza y vulnerabilidad) se encuentran en la definición de riesgo de lavado de activos aprobada por el regulador SBS («posibilidad de que la empresa sea utilizada para fines de LA/FT»). Comprendemos que la respuesta es afirmativa, se encuentran en la relación causal de riesgo entre la posibilidad y ser utilizado.

Es importante precisar que la vulnerabilidad para la empresa bancaria no debe ser entendida por el tipo penal lavado de activos o corrupción o defraudación tributaria o aduanera o trata de personas, etcétera. No es que un determinado tipo penal precedente al lavado de activos tenga un mayor o menor peso con relación a otro, sino que para la empresa bancaria será mayor o menor su vulnerabilidad en la medida que se hubiere lavado mayor o menor suma de dinero a través de los productos y servicios que ofrece. Esto se refleja en el número de transacciones que se generan, sean físicas o virtuales. Ello implica que el hecho de que haya tenido lugar LA/FT lleva a sostener que los controles desarrollados o mitigantes implementados no son lo suficientemente eficientes para aplacar la amenaza que constituye el lavado de activos.

Por lo tanto, el riesgo de lavado de activos constituye la posibilidad y consecuencia de incumplir con los objetivos de la empresa, determinado adicionalmente por dos indicadores: la amenaza (externa) y la debilidad o la vulnerabilidad (interna).

- Riesgo inherente: para el sujeto pasivo —entiéndase como empresa bancaria - será el riesgo propio o intrínseco de cada factor sin tener en cuenta la aplicación de un control.

- Los factores de riesgo de lavado de activos: comprendemos por factor al componente o elemento que actúa conjuntamente con otros para lograr su cometido. En el caso de las empresas bancarias, el de realizar operaciones de colocación y de captación de dinero. En el caso del lavador, el de conocer los factores para, a través de ellos, colocar su dinero mal habido.

Para una empresa bancaria, lo importante será poder determinar cuáles son esos factores que hacen posible la realización de operaciones de 
lavado de activos. Los más relevantes son: clientes, productos y servicios, canales y ubicación geográfica.

\section{IV.1.1. Cliente}

Sea que se trate de una persona natural o jurídica, sin importar que actúe a través de un representante o mandatario, lo que determina que dicha persona sea considerada cliente no es su condición de habitualidad ni la posesión de algún tipo de producto, sino el simple hecho de solicitar un servicio bancario o ser beneficiario del mismo.

Por lo expuesto, se aplicará la política de conocimiento por cada uno de los sujetos que participan en el acto jurídico, es decir, la persona natural o la persona jurídica o su representante o su mandatario. Todo lo vinculado al cliente se enmarca en el principio del conocimiento del cliente (KYC, por sus siglas en inglés), como desarrollaremos en las líneas siguientes.

NI DEJAR HACER NI DEJAR PASAR: EL COMPROMISO DE LAS INSTITUCIONES BANCARIAS PERUANAS FRENTE AL LAVADO

DE ACTIVOS A

TRAVÉS DE LA IMPLEMENTACIÓN DE UNA METODOLOGÍA POR RIESGO

\section{IV.1.1.1. Principio de conocimiento del cliente}

Para Ángela Toso, el riesgo de lavado de activos debe enfocarse a partir del deber de conocimiento del cliente. «El análisis del riesgo de lavado de activos se proyecta, en particular, al deber de conocimiento de los clientes. De este modo, si bien con carácter general debe determinarse la identidad y el perfil empresarial de todos los clientes, hay casos en que es necesario contar con procedimientos particularmente rigurosos de identificación y comprobación de su identidad» (2014, p. 408).

Lo indicado por la autora se enmarca dentro del enfoque basado en riesgo, debido a que remarca la distinción entre las entidades en función a su perfil empresarial. Con ello, cada entidad debe identificar su riesgo y aplicar una política específica de conocimiento del cliente que se adapte a su tipo de actividades. Por ejemplo, una entidad con enfoque en la banca comercial, cuyos clientes son en su mayoría grandes empresas, deberá implementar un sistema de conocimiento de los accionistas, directores, representantes legales y personas vinculadas, proveedores, mercado en el que opera el cliente, etcétera. A diferencia de esta, una compañía con enfoque en la banca personal deberá implementar un sistema que le permita conocer a la persona individualmente, como sus estudios, comprobar su centro de trabajo, si tiene otros ingresos, su pago de impuestos, etcétera.

Por su parte, el documento de consulta «Principios Básicos para una supervisión bancaria eficaz» del Comité de Supervisión Bancaria de Basilea (BCBS por sus siglas en inglés) ${ }^{17}$ establece lo siguiente en

17 Este documento contiene los parámetros mínimos para la correcta regulación y supervisión prudencial de bancos y sistemas bancarios. Este órgano está conformado por las autoridades de los entes de supervisión bancaria y bancos centrales de los países que conforman el G20.

DON'T LET IT

HAPPEN NOR

LET IT GO:THE

COMMITMENT

OF PERUVIAN

BANKING

INSTITUTIONS

AGAINST MONEY

LAUNDERING

THROUGHTHE

IMPLEMENTATION

OF AN AML RISK

ASSESSMENT

METHODOLOGY 
su Principio 29 sobre utilización abusiva de servicios financieros: «El supervisor determina que los bancos cuentan con políticas y procesos adecuados, incluidas estrictas reglas de debida diligencia con la clientela (CDD), para promover normas éticas y profesionales de alto nivel en el sector financiero e impedir que el banco sea utilizado, intencionalmente o no, con fines delictivos» (BCBS, 2012, p. 70). De esta manera, los bancos deberán incorporar en sus sistemas controles más rígidos para los casos que se consideren más riesgosos según la política de cada entidad, es decir, incorporar el principio de CDD con un enfoque basado en riesgos. Por ejemplo, deberían aplicarse más rigurosamente los controles respecto de las personas políticamente expuestas $(\mathrm{PEP})^{18}$ o de las transferencias del extranjero, entre otros supuestos.

El cuarto criterio esencial del Principio 29 del BCBS establece elementos principales para la gestión de conocimiento del cliente (CDD): a) «una política de admisión de clientes que identifica las relaciones comerciales que el banco no acepta», b) «un programa continuo de identificación, comprobación y diligencia debida; este programa incluye la verificación de la identidad de los titulares últimos...», así como su actualización; c) «políticas y procesos para vigilar y reconocer operaciones inusuales o potencialmente sospechosas», d) «una debida diligencia reforzada con cuentas de alto riesgo...»; e) «una debida diligencia reforzada con personas del ámbito político...»; y f) «reglas claras sobre qué registros mantener de la CDD y transacciones individuales y su período de retención» (BCBS, 2012, p. 71).

Dentro de los mismos criterios esenciales para la incorporación de las medidas de CDD, podemos mencionar, por ejemplo, la obligación de que sea la alta dirección quien decida si el banco establecerá o no relaciones comerciales con una PEP o si se van a mantener o abrir cuentas de alto riesgo. Los intermediarios financieros para llevar adelante la evaluación del cliente dentro de la política de conocimiento de cliente en el Perú han utilizado también las solicitudes de levantamiento del secreto bancario ordenado por el Poder Judicial a través del regulador SBS. El levantamiento del secreto bancario, al estar reconocido en la Constitución Política del Perú (1993), no es arbitrario y responde a la presunción de una falta cometida. Dicha presunción lleva al juez a averiguar sobre el patrimonio personal para garantizar, entre otras cosas, la reparación del daño. De esta manera se logra identificar al infractor local de un país. Asimismo, a nivel internacional se recurre a listas o bancos de datos de personas con tratamiento especial, las mal llamadas listas negras.

18 Por Resolución SBS 4349-2016 el regulador aprobó las funciones y cargos ocupados por personas expuestas políticamente PEP al LA/FT. 
En tal sentido, el adecuado conocimiento del cliente no termina en identificarlo cuando solicita un crédito o decide abrir una cuenta de ahorros, sino que es obligación del banco «aplicar medidas de "debida diligencia" (due diligence) o de "diligencia debida" a su respecto, para lograr un verdadero "conocimiento" del mismo [...] Una estrategia adecuada en este ámbito conlleva, además, el seguimiento permanente de las operaciones efectuadas por los clientes» (Toso, 2014, p. 406; las cursivas son nuestras). En consecuencia, el principio de conocimiento del cliente consiste en saber identificar y explicar por qué el cliente, sea persona natural o jurídica, tiene tal o cual patrimonio y si es razonable que el mismo fuese de su propiedad. En caso contrario, el intermediario financiero asume un riesgo que, sin ser legal, sí es un riesgo de reputación por el que podría ser sancionado económicamente.

\section{IV.1.2. Producto y servicios}

No importa el carácter del producto o servicio prestado, sea pasivo (cuenta corriente, depósito a plazo, cuenta de ahorro, etcétera), activo (préstamos en general otorgado por la empresa bancaria) o neutro (pago de servicios agua, luz, club, etcétera).

\section{IV.1.3. Canales}

Los canales pueden ser de dos tipos: a través de agencia, que sería la forma de transacción tradicional física, o la utilización de medios virtuales en todas sus modalidades.

\section{IV.1.4. Ubicación geográfica}

Se trata del espacio físico donde se realiza la transacción. Este puede ser nacional o internacional en relación con la ubicación territorial de la empresa bancaria.

\section{IV.2. Umbral de gestión por riesgo}

Tratándose del riesgo de lavado de activos, diera la impresión de que al referirnos a umbrales de gestión, fuésemos tolerantes con el riesgo de lavado de activos: que se puede tener lavadores dentro de la empresa bancaria y no pasa nada. Ese no es el sentido de la afirmación en absoluto, más bien lo que afirmamos es lo siguiente.

En la medida en que se está empoderando la aplicación subjetiva, es decir, el juicio experto — conformado por la experiencia, el compromiso de la empresa bancaria, la capacitación del personal en general en temas de prevención de LA/FT - para pasar a un nivel superior, de mejores prácticas cuantitativas o cuasi-cuantitativas, entonces es factible referirse a umbrales de gestión. Esto implica aplicar mayores controles de debida diligencia mejorada para mitigar el riesgo más alto y, controles medios o menores para los riesgos medios o bajos identificados.

NI DEJAR HACER NI DEJAR PASAR: EL COMPROMISO DE LAS INSTITUCIONES BANCARIAS PERUANAS FRENTE AL LAVADO

DE ACTIVOS A

TRAVÉS DE LA IMPLEMENTACIÓN DE UNA

METODOLOGÍA POR RIESGO

DON'T LET IT

HAPPEN NOR

LET IT GO:THE COMMITMENT OF PERUVIAN

BANKING

INSTITUTIONS AGAINST MONEY LAUNDERING THROUGHTHE IMPLEMENTATION OF AN AML RISK ASSESSMENT METHODOLOGY 


\section{IV.3. Aplicación de controles}

Dentro del marco de la aplicación de una Metodología de Gestión por Riesgo en LA/FT, los controles son preventivos, de detección o de mitigación o compensación. Los preventivos se encuentran en el inicio de la relación comercial, cuando el cliente solicitante de un servicio o producto se presenta como tal y el intermediario financiero bancario inicia el proceso de validación de la información personal brindada por aquel potencial cliente.

El control de detección se presenta luego de haber concluido la etapa de control preventivo y en relación con los productos o servicios utilizados por el cliente. Se aprecia que el uso de los productos o servicios no corresponde con la información inicialmente brindada por el cliente. En otras palabras, lo que dice no coincide con lo que hace.

Finalmente, la mitigación o compensación se da cuando, pese a los controles previos para evitar el lavado de activos, la empresa no ha sido capaz de identificar la transacción sospechosa porque fue sorprendida por el lavador de activos, quien burló los controles preestablecidos. Es importante precisar que no se trata de un caso en el que no hay controles, sino que estos fueron burlados o sorteados.

\section{IV.4. Monitoreo del riesgo LA/FT}

En primer lugar, resulta pertinente desmentir la opinión —compartida originalmente por muchos cuando empezó a discutirse la prevención del lavado de activos en el Perú- de que el monitoreo del riesgo de LA/ FT significa contar con un soporte informático, o programa, que arroje automáticamente (por el simple hecho de aplicar la «función continuar») una operación bancaria de lavado de activos para ser reportada a la UIFPerú. Lo que en realidad hemos venido observando es que los programas ofrecidos en el mercado son de monitoreo de transacciones bancarias de falsos positivos.

Por ello, resulta tan complejo hablar de monitoreo del riesgo de LA/FT. El monitoreo exige contar antes con una Metodología de Identificación de Riesgo de Lavado de Activos, con una matriz de valoración del riesgo de aplicación operativa; la misma que luego se convertirá en una Metodología de Identificación y Valorización por Riesgo. Como producto de la aplicación de la metodología, se producirá un informe técnico de prevención de LA/FT, donde se señalará el nivel de riesgo asumido por la empresa bancaria, sus fortalezas, debilidades y oportunidades de mejora con relación a los factores clientes, productos, servicios, canales y ubicación geográfica, debiéndose establecer plazos para la revisión de la metodologías por riesgo (entre 4 a 5 años y la revisión de los factores de 1 a 2 años). 
Por ello, como parte de la aplicación de las políticas internas, la herramienta que nos permitirá mejorar la utilización de información para las empresas del sistema financiero, con énfasis en los bancos, es la aplicación de una Metodología de Identificación y Evaluación por Riesgo en Prevención de Lavado de Activos.

A continuación y como anexo, presentamos un caso que no dista mucho de la realidad en relación con el lavado de activos y aplicamos la metodología por riesgo.

\section{ANEXO}

\section{V.1. Presentación del caso}

La empresa JJK, constituida bajo la legislación del Perú, desea ser cliente del Banco Buena Fe que es una entidad financiera transnacional que viene operando el nuestro medio desde el año 2000. Para ello, la empresa debe cumplir con una serie de requisitos del banco, este proceso se conoce como «el inicio de la relación comercial». La empresa tiene por giro principal la elaboración de productos farmacéuticos, constituida hace 2 años, gestiona su objeto social a través de servicios de transferencias interbancarias de bancos corresponsales, compra venta de moneda extranjera (en efectivo), declara que tiene negocios con localidades de América Latina y, en especial, con paraísos financieros. Por otro lado, con respecto a los productos pasivos, solicita el uso de cuenta de ahorro y corriente. Sobre la composición de su accionariado, declara que su principal accionista es una persona jurídica con acciones al portador, constituida en un país de alto riesgo político y acusada de venta de armas de destrucción masiva, además, dicha persona tiene una participación del $80 \%$ del capital de la empresa JJK.

\section{V.2. Metodología de identificación y evaluación de riesgos en prevención de lavado de activos \\ 1. Introducción \\ 1.1. Alcance}

La Metodología de Identificación y Evaluación de Riesgos en Prevención de Lavado de Activos (MIR) es aplicable para una empresa de operaciones múltiples en general (banco) y tiene por objeto detallar los procedimientos que deberán seguir los involucrados en las operaciones realizadas, para la atención de sus clientes, en la identificación por riesgo de lavado de activos.

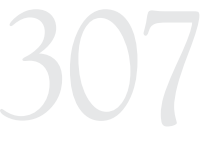

NI DEJAR HACER NI DEJAR PASAR: EL COMPROMISO DE LAS INSTITUCIONES BANCARIAS PERUANAS FRENTE AL LAVADO

DE ACTIVOS A

TRAVÉS DE LA IMPLEMENTACIÓN DE UNA

METODOLOGÍA POR RIESGO

\section{DON'T LET IT}

HAPPEN NOR

LET IT GO:THE COMMITMENT OF PERUVIAN

BANKING

INSTITUTIONS AGAINST MONEY LAUNDERING THROUGHTHE IMPLEMENTATION OF AN AML RISK ASSESSMENT METHODOLOGY 
La normativa comprende a todos los representantes, funcionarios, empleados y personal que directa o indirectamente estén relacionados con las labores que realiza la empresa.

Con relación al caso propuesto, el Banco Buena Fe calza dentro de la metodología.

\subsection{Marco legal}

El banco es una sociedad autorizaday supervisada por la Superintendencia de Banca, Seguros y AFP que tiene como actividad económica principal la intermediación bancaria, consistente en «recibir dinero del público en depósito o bajo cualquier modalidad contractual, y en utilizar ese dinero, su propio capital y el que obtenga de otras fuentes de financiación en conceder créditos en las diversas modalidades» (ley 26702, artículo 282, numeral 1).

El Banco Buena Fe, conforme a la legislación del Perú, opera como una empresa de banca múltiple.

\subsection{Aspectos generales}

La metodología descrita en la presente normativa está ordenada en función de los principales procesos operativos, de negocio, de control y cumplimiento que se llevan a cabo para la atención de sus clientes, tomando como base la política de conocimiento del cliente y del mercado que debe hacer suya el mismo banco.

- De procedimientos operativos:

- Mejoramiento de la base de datos de clientes antiguos (data 100\% actualizada del cliente)

- Registro de cliente nuevos (data 100\% actualiza del cliente)

- De procedimientos comerciales:

- Segmentación de clientes

- Productos y servicios bancarios

- De procedimiento de control y cumplimiento:

- Aprobación, revisión y monitoreo de transacciones de clientes vinculados (propiedad, gestión)

- Banco de datos de personas con tratamiento especial (listas de clientes calificados como PEP, comunicaciones del Ministerio Público y Poder Judicial, otros) 
Cada una de estas secciones de procesos establece la metodología que deben seguir las áreas involucradas en su trabajo diario. La gerencia general y las jefaturas del banco deben asegurarse de que la normativa se encuentre actualizada.

NI DEJAR HACER NI

DEJAR PASAR: EL

COMPROMISO DE

Es de comprender del caso propuesto del Banco Buena Fe que el regulador Superintendencia de Banca, Seguros y AFP, en cada oportunidad que evalúa el sistema de prevención de lavado de activos en su visita anual, lo que realmente hace es verificar el o los procesos y la efectividad de los mismos para mitigar el riesgo de lavado de activos.

LAS INSTITUCIONES

BANCARIAS

PERUANAS FRENTE

AL LAVADO

DE ACTIVOS A

TRAVÉS DE LA

IMPLEMENTACIÓN

DE UNA

METODOLOGÍA

\subsection{Objetivo}

Gestionar el riesgo del lavado de activos mediante la identificación, medición, control y monitoreo del riesgo presente en los clientes, productos, servicios, canales de distribución y ubicaciones geográficas

Elaborar y efectuar procedimientos y controles internos idóneos como respuesta al riesgo identificado

En los modelos actuales de prevención de lavado de activos, las estructuras descansan en tres líneas de defensa: la primera formada por el front office, que vendría ser toda la red de agencias, sus áreas comerciales, que tiene el primer contacto con el cliente. La segunda línea de defensa se conoce como las áreas de gobierno, las gerencias o unidades de cumplimiento en prevención de lavado de activos. Su labor exclusiva es ver el cumplimiento de las políticas que posee la empresa bancaria en el tema de prevención de lavado de activos. La tercera línea, la auditoría interna, se dedica a verificar el cumplimiento de la política por las áreas comerciales (primera línea) dispuesta por la segunda línea de defensa y que la misma sea efectiva.

En el caso propuesto, comprendemos que se cumple con la estructura de tres líneas de defensa por parte del Banco Buena $\mathrm{Fe}$, lo que implicaría hacer suya las mejores prácticas en prevención de LA/FT.

\section{Administración del riesgo}

Para la administración del riesgo, lo relevante es empezar por los factores y las variables. 


\subsection{Factores de riesgos}

Conforman, de una manera resumida, las características que integran la forma en que operan los productos y servicios, y que pueden utilizarse para medir su grado de exposición al riesgo.

Tabla 3

\begin{tabular}{|c|c|c|c|}
\hline Factor & Segmento & Variables & Subvariables \\
\hline \multirow{2}{*}{ Cliente } & \multirow{2}{*}{ Tipo de persona } & Natural & $\begin{array}{l}\text { acionales } \\
\text { xtranjeros }\end{array}$ \\
\hline & & Jurídico & $\begin{array}{l}\text { acionales } \\
\text { xtranjeros }\end{array}$ \\
\hline \multirow{4}{*}{$\begin{array}{l}\text { Productos y } \\
\text { servicios }\end{array}$} & \multirow{4}{*}{$\begin{array}{l}\text { Servicio de interme- } \\
\text { diación }\end{array}$} & Pasivos & $\begin{array}{l}\text { pósitos } \\
\text { eicomisos }\end{array}$ \\
\hline & & $\begin{array}{l}\mathrm{P} \\
\mathrm{T} \\
\mathrm{C} \\
\mathrm{H} \\
\mathrm{L} \\
\mathrm{P} \\
\mathrm{p} \\
\mathrm{P} \\
\mathrm{n}\end{array}$ & $\begin{array}{l}\text { stamos (en general) } \\
\text { jetas de crédito } \\
\text { nercio exterior } \\
\text { otecarios } \\
\text { sing } \\
\text { ductos activos para em- } \\
\text { sas } \\
\text { stamos para pequeña y } \\
\text { diana empresa }\end{array}$ \\
\hline & & Inversión & dos mutuos \\
\hline & & Servicios & $\begin{array}{l}h \text { Management } \\
\text { rcado de capitales }\end{array}$ \\
\hline \multirow{2}{*}{$\begin{array}{l}\text { Canales de } \\
\text { distribución }\end{array}$} & $\begin{array}{l}\text { Red de agencias del } \\
\text { banco }\end{array}$ & \multicolumn{2}{|c|}{$\begin{array}{l}\text { Operaciones físicas (uso del dinero en efec- } \\
\text { tivo) }\end{array}$} \\
\hline & $\begin{array}{l}\text { Banca por internet } \\
\text { (uso de la web) }\end{array}$ & $\begin{array}{l}\text { Operaciones vir- } \\
\text { tuales }\end{array}$ & $\begin{array}{l}\text { Por ingresos mediante } \\
\text { otros bancos }\end{array}$ \\
\hline \multirow{4}{*}{$\begin{array}{l}\text { Ubicación } \\
\text { geográfica }\end{array}$} & \multirow[b]{2}{*}{ Nacional } & \multicolumn{2}{|l|}{ Regiones } \\
\hline & & \multicolumn{2}{|l|}{$\begin{array}{l}\text { Provincias } \\
\text { Distritos }\end{array}$} \\
\hline & \multirow{2}{*}{ Internacional } & \multirow{2}{*}{ No residentes } & $\begin{array}{l}\text { Países cooperantes en } \\
\text { Prevención de Lavado } \\
\text { de Activos }\end{array}$ \\
\hline & & & $\begin{array}{l}\text { Países no cooperantes } \\
\text { en Prevención de La- } \\
\text { vado de Activos }\end{array}$ \\
\hline \multicolumn{4}{|c|}{$\begin{array}{l}\text { Listas } \\
\text { Comunicaciones periodísticas, del Poder Judicial, del Ministerio Público, comunicaciones } \\
\text { policiales, otras. Contienen información relevante por actos o posibles actos realizados al } \\
\text { margen de la ley. }\end{array}$} \\
\hline
\end{tabular}


- Tipo de cliente: clasificación de la persona natural o jurídica de acuerdo con el segmento al que pertenece. Dentro de las personas jurídicas (PJ), están las PJ nacionales y PJ extranjeras. De este último grupo, las personas jurídicas que no tienen poderes inscritos en Registros Públicos deben operar a través de un(os) representante(s) que también deben ser considerados clientes y evaluados en forma independiente de quien representa.

- Número de casos: información histórica de las alertas generadas por los clientes.

- Número de transacciones bancarias: cualquier tipo de operación de dinero en que interviene un banco (pago con tarjeta de crédito o de débito, cobro de cheque, retiro de cuenta de ahorro, depósito a plazo, otros).

- Monto: importe acumulado de la alerta generada.

- Antigüedad: tiempo de inicio de relación con la institución.

- Nacionalidad: país de procedencia de la persona.

- HEC (Hoja de Evaluación de Clientes): formato elaborado por la empresa bancaria que contiene documentos requeridos para acreditar la procedencia del dinero y mitigar con ello riesgos.

- KYC (conocimiento del cliente, KYC por las siglas en inglés): información que mantiene el funcionario de negocios del cliente, respecto de la aplicación de la política de conocimiento del cliente y de mercado.

\subsubsection{Productos y servicios:}

- Captación: es considerada una operación pasiva para un banco, consiste en recolectar dinero de las personas naturales o jurídicas.

- Colocación: es considerada una operación activa para un banco, consiste en otorgar un préstamo.

- Servicio: no encaja necesariamente como captación o colocación, se ubica todo tipo de operación relacionada al cobro de comisión.

\subsubsection{Canales de distribución:}

- Oficinas o agencias (ubicadas dentro de un territorio): se determinó que las transacciones realizadas en las oficinas que tienen como procesos el abono o transferencias en cuentas del banco y son consideradas como ingresos de efectivo tienen un mayor nivel de riesgo.

- Web, todo lo vinculado con la banca electrónica.

NI DEJAR HACER NI

DEJAR PASAR: EL

COMPROMISO DE

LAS INSTITUCIONES

BANCARIAS

PERUANAS FRENTE

AL LAVADO

DE ACTIVOS A

TRAVÉS DE LA

IMPLEMENTACIÓN

DE UNA

METODOLOGÍA

POR RIESGO

DON'T LET IT

HAPPEN NOR

LET IT GO:THE

COMMITMENT

OF PERUVIAN

BANKING

INSTITUTIONS

AGAINST MONEY

LAUNDERING

THROUGHTHE

IMPLEMENTATION

OF AN AML RISK

ASSESSMENT

METHODOLOGY 


\subsubsection{Zona geográfica (localidad del cliente):}

- Nacional (región, provincia y distrito): identificación de la localidad a la cual pertenece la cuenta del cliente.

- Internacional (no residente): las operaciones son de clientes o realizadas a través de terceros o representantes, identificando a los países cooperantes y no cooperantes en prevención de lavado de activos.

\subsubsection{Listas:}

- Comunicaciones del Ministerio Público o del Poder Judicial vía la Superintendencia de Banca y Seguros: investigaciones o procesos judiciales asociados al lavado de activos y financiamiento al terrorismo.

- ROS (reporte de operación sospechosa) / Lista de Personas con Tratamiento Especial: información de las personas naturales o jurídicas a las cuales se les realizó una nota informativa por operación sospechosa informándose de ello a la UIF; información relevante por noticias periodísticas vinculada con actos al margen de la ley.

- Programas de búsqueda masiva: sistema web con el cual se realiza la comparación del nombre y apellido de un cliente contra los nombres de personas de una base negativa a nivel mundial.

\subsection{Mapa de evaluación de riesgos}

Nos permite identificar las amenazas, vulnerabilidades y riesgos sobre los servicios, clientes, canales de distribución y ubicación geográfica, con el fin de generar un plan de implementación de los controles que aseguren el cumplimiento de las normas legales y las mejores prácticas, así como supervisar su aplicación.

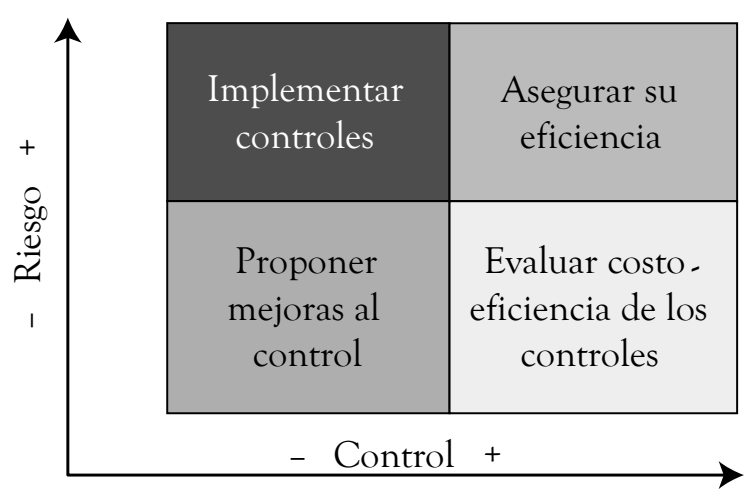




\subsection{Calificación de riesgos}

\subsubsection{Probabilidad de riesgo}

Puede describirse la probabilidad como alta, media y baja de que el riesgo ocurra. Los factores a tomarse en cuenta para determinar la probabilidad de ocurrencia son los siguientes: origen de la amenaza, la naturaleza de la vulnerabilidad, mecanismos de control y su relación con la eficacia de estos.

\subsubsection{Impacto del riesgo}

La magnitud del impacto puede ser calificada como alta, media o baja. Se trata del impacto probable que podría tener el riesgo sobre la empresa en caso el mismo ocurriera. No todas las amenazas tiene el mismo nivel de impacto porque cada sistema de organización tiene valor distinto.

La relación de la probabilidad y el impacto permiten determinar el peso de cada factor de riesgo.

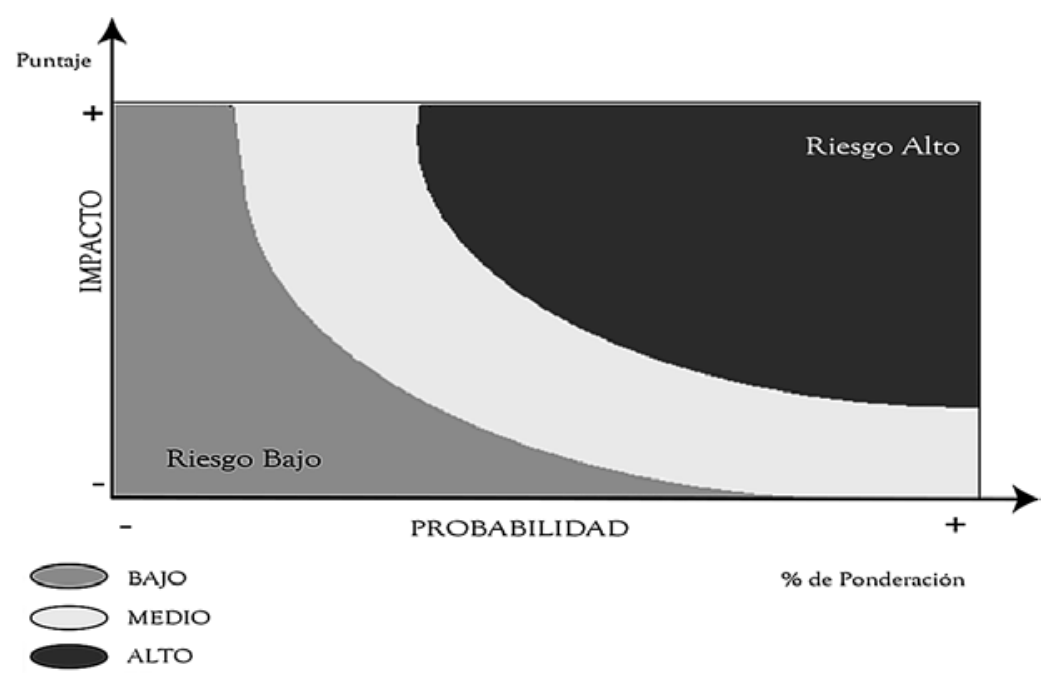

NI DEJAR HACER NI

DEJAR PASAR: EL

COMPROMISO DE

LAS INSTITUCIONES

BANCARIAS

PERUANAS FRENTE

AL LAVADO

DE ACTIVOS A

TRAVÉS DE LA

IMPLEMENTACIÓN

DE UNA

METODOLOGÍA

POR RIESGO

DON'T LET IT

HAPPEN NOR

LET IT GO:THE

COMMITMENT

OF PERUVIAN

BANKING

INSTITUTIONS

AGAINST MONEY

LAUNDERING

THROUGHTHE

IMPLEMENTATION

OF AN AML RISK

ASSESSMENT

METHODOLOGY

\subsubsection{Medición del riesgo}

Se asignará una ponderación a cada indicador por su probabilidad de riesgo como e impacto determinado en la generación de los casos dependiendo del nivel de riesgo que representa y se obtendrá un promedio que servirá de parámetro para clasificar el grado de riesgo de los clientes. 


\begin{tabular}{|l|l|l|}
\hline Valor & \multicolumn{2}{|c|}{ Rango de probabilidad de riesgo de LA/FT } \\
\hline 5 & $\begin{array}{l}\text { Faltan parámetros } \\
\text { necesarios o son incorrectos }\end{array}$ & Muy frecuente $(>6)$ \\
\hline 4 & $\begin{array}{l}\text { Faltan parámetros } \\
\text { necesarios o son incorrectos }\end{array}$ & Probable (5-6) \\
\hline 3 & $\begin{array}{l}\text { Faltan parámetros } \\
\text { necesarios o son incorrectos }\end{array}$ & Puede ocurrir (3-4) \\
\hline 2 & $\begin{array}{l}\text { Faltan parámetros } \\
\text { necesarios o son incorrectos }\end{array}$ & Eventual (2) \\
\hline 1 & $\begin{array}{l}\text { Faltan parámetros } \\
\text { necesarios o son incorrectos }\end{array}$ & Rara vez (1) \\
\hline
\end{tabular}

\begin{tabular}{|l|l|l|}
\hline Valor & \multicolumn{2}{|c|}{ Rango de impacto } \\
\hline 5 & $\begin{array}{l}\text { Faltan parámetros } \\
\text { necesarios o son incorrectos }\end{array}$ & Alto $>6$ ) \\
\hline 4 & $\begin{array}{l}\text { Faltan parámetros } \\
\text { necesarios o son incorrectos }\end{array}$ & Mayor (5-6) \\
\hline 3 & $\begin{array}{l}\text { Faltan parámetros } \\
\text { necesarios o son incorrectos }\end{array}$ & Moderado (3-4) \\
\hline 2 & $\begin{array}{l}\text { Faltan parámetros } \\
\text { necesarios o son incorrectos }\end{array}$ & Menor (2) \\
\hline 1 & $\begin{array}{l}\text { Faltan parámetros } \\
\text { necesarios o son incorrectos }\end{array}$ & No significativo (1) \\
\hline$\bigcirc$ & & \\
\hline
\end{tabular}




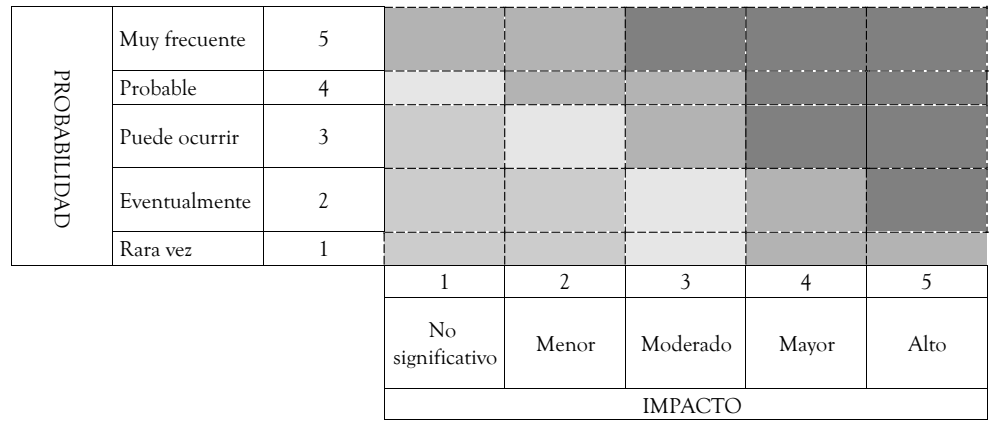

\section{Análisis de los factores de riesgo}

\subsection{Productos y servicios}

Del análisis de riesgo del factor productos y servicios, se determina en la labor de monitoreo de transacciones que el ingreso en efectivo a través de los diferentes productos que se ofrece representa un mayor nivel de riesgo. Por esta razón, consideramos necesario realizar un análisis más detallado en los productos abajo señalados, con el propósito de establecer el procedimiento a seguir en el cierre de casos generados, de tal forma que no se distraiga la atención en casos que no reviertan mayor riesgo, por las características presentadas en su generación.

\begin{tabular}{|c|c|c|}
\hline Productos y/o servicios & $\begin{array}{c}\text { Ponderación } \\
\text { total del riesgo } \\
(\%)\end{array}$ & $\begin{array}{l}\text { Nivel de riesgo } \\
\text { estadístico/juicio experto }\end{array}$ \\
\hline Producto y/o servicio 1 & & $\begin{array}{l}3 \text { (faltan parámetros necesarios } \\
\text { o son incorrectos) }\end{array}$ \\
\hline Producto y/o servicio 2 & & $\begin{array}{l}3 \text { (faltan parámetros necesarios } \\
\text { o son incorrectos) }\end{array}$ \\
\hline Producto y/o servicio 3 & 0 & 2 \\
\hline Producto y/o servicio 4 & 0 & 2 \\
\hline Producto y/o servicio 5 & & 1 \\
\hline Total & $100.00 \%$ & \\
\hline
\end{tabular}

- Cálculo de la ponderación total por riesgo:

La ponderación por tipo de producto se ha calculado en función al monto total en un período (horas, días, semanas, meses, años).

\subsection{Clientes}

Del análisis de riesgo del factor clientes, se determinó que el riesgo estará asociado al segmento al cual pertenece el cliente.
NI DEJAR HACER NI DEJAR PASAR: EL COMPROMISO DE LAS INSTITUCIONES BANCARIAS PERUANAS FRENTE AL LAVADO

DE ACTIVOS A

TRAVÉS DE LA IMPLEMENTACIÓN DE UNA

METODOLOGÍA POR RIESGO

DON'T LET IT

HAPPEN NOR

LET IT GO:THE COMMITMENT OF PERUVIAN

\section{BANKING}

INSTITUTIONS

AGAINST MONEY

LAUNDERING

THROUGHTHE

IMPLEMENTATION OF AN AML RISK ASSESSMENT METHODOLOGY 


\begin{tabular}{|c|c|c|}
\hline Tipo de cliente & $\begin{array}{c}\text { Ponderación } \\
\text { total del } \\
\text { riesgo }(\%)\end{array}$ & $\begin{array}{l}\text { Nivel de riesgo } \\
\text { estadístico/iuicio } \\
\text { experto }\end{array}$ \\
\hline Persona natural adinerada (retail) & & 3 \\
\hline Persona natural receptiva (baja cartera) & & 2 \\
\hline Persona jurídica local (no institucional) & & 3 \\
\hline Persona jurídica local (institucional) & & 1 \\
\hline $\begin{array}{l}\text { Persona jurídica extranjera (institucional } \\
\text { funcionario de negocios internacionales) }\end{array}$ & & 1 \\
\hline Persona jurídica extranjera adinerada & & 3 \\
\hline Total & $100.00 \%$ & \\
\hline
\end{tabular}

- Criterios para determinar la ponderación total del riesgo:

1. A los clientes institucionales extranjeros y locales, por tener un régimen de clientes regulados por otras instituciones, se les asignará discrecionalmente una probabilidad mínima de ocurrencia de 1.

2. En función a la segmentación de los demás clientes, se asignará una ponderación que dependerá del número de clientes de cada segmento.

3. En función al monto de las operaciones que realiza cada segmento, se le generará otra ponderación para tener en cuenta la relevancia del segmento.

4. La ponderación final será la combinación de los criterios 2 y 3.

\subsection{Canales de distribución}

Del análisis de riesgo por el factor canales de distribución, se determinó, por ejemplo, que las transacciones realizadas en la oficina de ciudad 1 , oficina ciudad 2, oficina ciudad 3 y oficina ciudad 4 (ingresos de efectivo) tienen un mayor nivel de riesgo.

\begin{tabular}{|c|c|c|}
\hline Canal de distribución & $\begin{array}{c}\text { Ponderación } \\
\text { total del } \\
\text { riesgo }(\%)\end{array}$ & $\begin{array}{l}\text { Nivel de riesgo } \\
\text { estadístico/juicio } \\
\text { experto }\end{array}$ \\
\hline Oficina ciudad 1 & 0 & 4 \\
\hline Oficina ciudad 2 & 0 & 2 \\
\hline Oficina ciudad 3 & 0 & 4 \\
\hline Oficina ciudad 4 & 0 & 4 \\
\hline Totales & $100 \%$ & \\
\hline
\end{tabular}


- Criterios para determinar la ponderación total del riesgo:

La ponderación total del riesgo se calcula en función, por ejemplo, de la cantidad de clientes que tiene cada oficina, servicios de transferencias interbancarias de bancos corresponsales, compra venta de moneda extranjera (en efectivo), la declaración de negocios con localidades o zonas específicas de alto riesgo que no colaboran o que tienen deficientes mecanismos de control y prevención en lavado de activos, financiamiento del terrorismo o en venta de armas de destrucción masiva.

En el caso propuesto, la empresa JJK realiza operaciones interbancarias a través de bancos corresponsales (no especifica la razón, ni frecuencia, ni el monto de las mismas). Realiza operaciones en un paraíso financiero (no especifica el tipo de operaciones). Sobre la cuenta de ahorro y corriente, no especifica la procedencia del dinero ni la periodicidad de las transacciones.

\subsection{Zonas geográficas}

Hay muchas formas de efectuar la evaluación por zona geográfica para una empresa bancaria, una de ella es, por ejemplo, la que se utiliza en Estados Unidos, la lista OFAC o lista del tesoro americano. En ella se registra el nombre de aquellas personas (naturalesojurídicas) relacionadas con el narcotráfico, obligando a las empresas norteamericanas a no realizar con dichas personas ningún tipo de acto comercial, bajo sanción administrativa y penal de sus representantes, accionistas y trabajadores, estando facultados a retener los fondos si hay elementos para considerar que la transacción puede tener un origen ilegal.

En el caso del Perú, se ha elaborado otro análisis de riesgo para el factor zona geográfica sobre la base de la información presentada por el Ministerio Público (Observatorio de Criminalidad, 2011), el cual recoge veinticinco tipos de delitos, entre ellos los vinculados al lavado de activos. Asimismo, se ha recurrido a la información brindada por Cedro (2011) sobre puntos de comercialización y consumo de drogas en el país. Asimismo, se ha considerado las comunicaciones a la UIF-Perú a través de los Reportes de Operaciones Sospechosas (ROS).

NI DEJAR HACER NI

DEJAR PASAR: EL

COMPROMISO DE

LAS INSTITUCIONES

BANCARIAS

PERUANAS FRENTE

AL LAVADO

DE ACTIVOS A

TRAVÉS DE LA

IMPLEMENTACIÓN

DE UNA

METODOLOGÍA

POR RIESGO

DON'T LET IT

HAPPEN NOR

LET IT GO:THE

COMMITMENT

OF PERUVIAN

BANKING

INSTITUTIONS

AGAINST MONEY

LAUNDERING

THROUGHTHE

IMPLEMENTATION

OF AN AML RISK

ASSESSMENT

METHODOLOGY 


\begin{tabular}{|l|c|}
\hline \multicolumn{1}{|c|}{ Participación riesgo } & Ponderación* \\
\hline Microcomercialización de drogas & $30 \%$ \\
\hline Infracciones contra la Administración Pública (corrupción) & $20 \%$ \\
\hline Trata de personas & $20 \%$ \\
\hline Tráfico de armas & $15 \%$ \\
\hline Riesgo general (incidencia delictiva) $\rightarrow$ 25 delitos & $15 \%$ \\
\hline Total & $100 \%$ \\
\hline
\end{tabular}

" Pesos asignados sobre la base del juicio experto

Riesgo en materia de PLA por zona geográfica (departamentos)

\begin{tabular}{|c|c|c|c|}
\hline \multirow{2}{*}{ Departamentos } & \multirow{2}{*}{ Ponderación } & \multicolumn{2}{|c|}{ Niveles de riesgo } \\
\hline & & Descripción & Símbolo \\
\hline $\begin{array}{l}\text { Lima } \\
\text { Lambayeque }\end{array}$ & 5 & Riesgo alto & \\
\hline \multicolumn{4}{|l|}{ Arequipa } \\
\hline \multicolumn{4}{|l|}{ La Libertad } \\
\hline \multicolumn{4}{|l|}{ Piura } \\
\hline \multicolumn{4}{|l|}{ Lima Norte } \\
\hline \multicolumn{4}{|l|}{ Huaura } \\
\hline Ica & \multirow{7}{*}{4} & \multirow{7}{*}{ Riesgo medio alto } & \\
\hline Huánuco & & & \\
\hline \multicolumn{2}{|l|}{ Lima sur } & & \\
\hline \multicolumn{2}{|l|}{ Cajamarca } & & \\
\hline \multicolumn{2}{|l|}{ Callao } & & \\
\hline \multicolumn{2}{|l|}{ Loreto } & & \\
\hline \multicolumn{2}{|l|}{ Ucayali } & & \\
\hline \multicolumn{4}{|l|}{ Junín } \\
\hline \multicolumn{4}{|l|}{ Cusco } \\
\hline \multicolumn{4}{|l|}{ Amazonas } \\
\hline \multicolumn{4}{|l|}{ Puno } \\
\hline \multicolumn{4}{|l|}{ Santa } \\
\hline Ayacucho & 3 & Riesgo medio & \\
\hline \multicolumn{4}{|l|}{ Moquegua } \\
\hline \multicolumn{4}{|l|}{ San Martín } \\
\hline \multicolumn{4}{|l|}{ Apurímac } \\
\hline \multicolumn{4}{|l|}{ Cañete } \\
\hline \multicolumn{4}{|l|}{ Tumbes } \\
\hline \multicolumn{4}{|l|}{ Tacna } \\
\hline \multicolumn{4}{|l|}{ Áncash } \\
\hline Madre de Dios & 2 & Riesgo bajo medio & \\
\hline \multicolumn{4}{|l|}{ Huancavelica } \\
\hline Pasco & & & \\
\hline
\end{tabular}


Distribución del riesgo por departamentos del Perú

$17 \%$

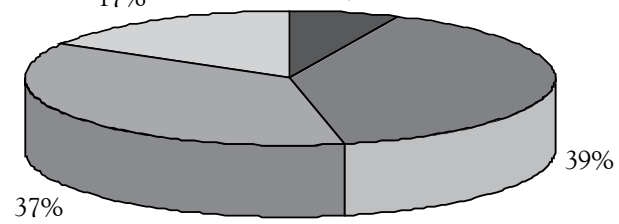

Riesgo Alto

Riesgo Medio Alto

Riesgo Medio

Riesgo Bajo Medio

Riesgo Bajo

Fuente: Cedro. El problema de las drogas en el Perú, 2011. Elaboración propia.

Riesgo en materia de PLA

por zona geográfica (departamento)

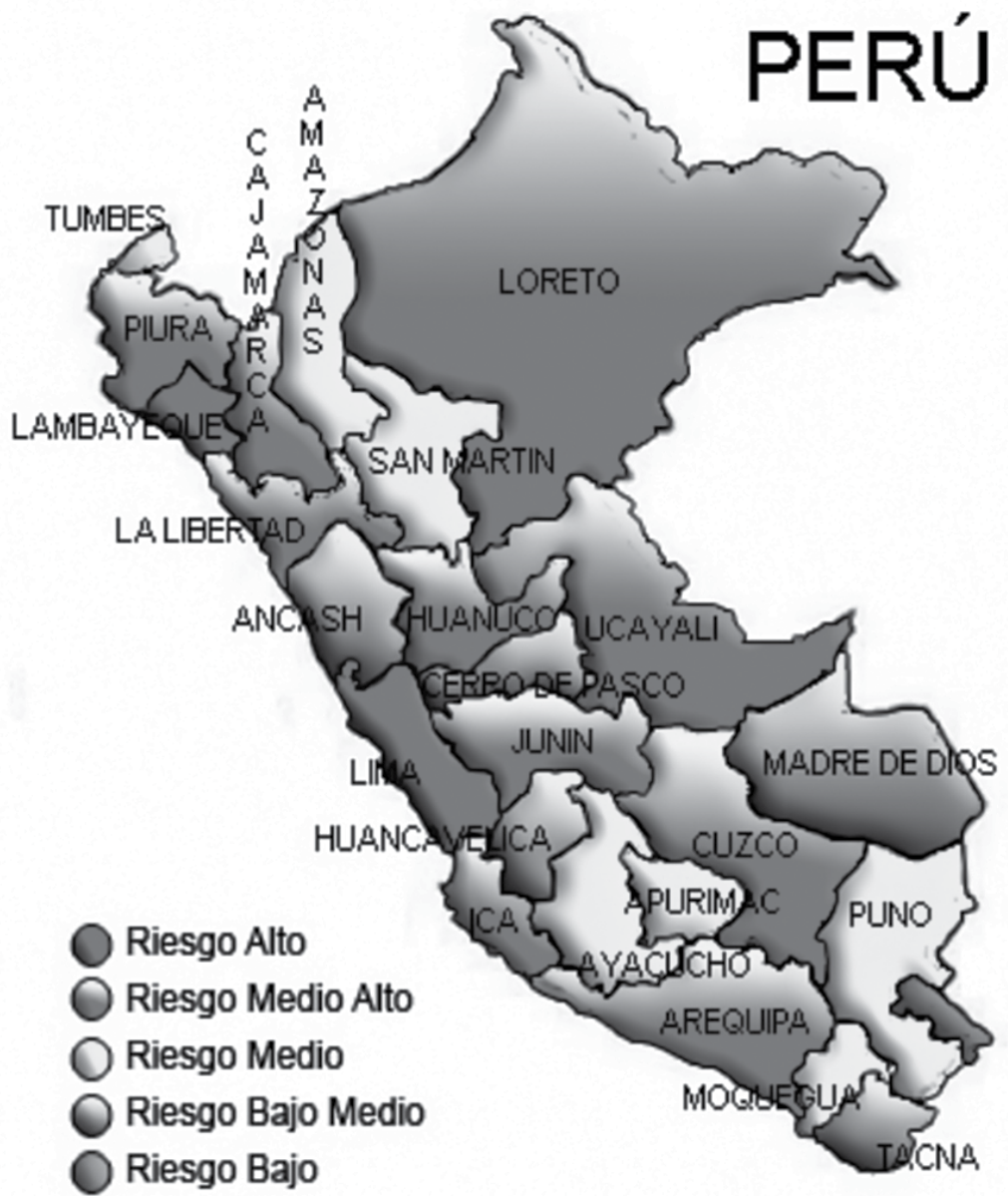

210

NI DEJAR HACER NI DEJAR PASAR: EL

COMPROMISO DE

LAS INSTITUCIONES

BANCARIAS

PERUANAS FRENTE

AL LAVADO

DE ACTIVOS A

TRAVÉS DE LA

IMPLEMENTACIÓN

DE UNA

METODOLOGÍA

POR RIESGO

DON'T LET IT

HAPPEN NOR

LET IT GO:THE

COMMITMENT

OF PERUVIAN

BANKING

INSTITUTIONS

AGAINST MONEY

LAUNDERING

THROUGHTHE

IMPLEMENTATION

OF AN AML RISK

ASSESSMENT

METHODOLOGY 
Riesgo en materia de PLA por zona geográfica - Lima (distritos)

\begin{tabular}{|c|c|c|c|}
\hline \multirow{2}{*}{ Distritos } & \multirow{2}{*}{ Ponderación } & \multicolumn{2}{|c|}{ Niveles de riesgo } \\
\hline & & Descripción & Símbolo \\
\hline La Victoria & \multirow{10}{*}{5} & \multirow{10}{*}{ Riesgo alto } & \\
\hline Comas & & & \\
\hline San Juan de Lurigancho & & & \\
\hline Cercado de Lima & & & \\
\hline Rímac & & & \\
\hline San Martín de Porres & & & \\
\hline El Agustino & & & \\
\hline Ventanilla & & & \\
\hline Los Olivos & & & \\
\hline Barranco & & & \\
\hline San Miguel & \multirow{9}{*}{4} & \multirow{9}{*}{ Riesgo medio alto } & \\
\hline Breña & & & \\
\hline Independencia & & & \\
\hline San Juan de Miraflores & & & \\
\hline Lince & & & \\
\hline La Perla & & & \\
\hline Santa Anita & & & \\
\hline Chorrillos & & & \\
\hline Miraflores & & & \\
\hline Puente Piedra & \multirow{6}{*}{3} & \multirow{6}{*}{ Riesgo medio } & \\
\hline Villa El Salvador & & & \\
\hline Surquillo & & & \\
\hline Ate & & & \\
\hline Magdalena del Mar & & & \\
\hline San Borja & & & \\
\hline Surco & \multirow{8}{*}{2} & \multirow{8}{*}{ Riesgo bajo medio } & \\
\hline Pueblo Libre & & & \\
\hline San Isidro & & & \\
\hline Jesús María & & & \\
\hline Ancón & & & \\
\hline Carabayllo & & & \\
\hline Bellavista & & & \\
\hline Villa María del Triunfo & & & \\
\hline San Luis & \multirow{5}{*}{1} & \multirow{5}{*}{ Riesgo bajo } & \\
\hline Carmen de la Legua & & & \\
\hline La Molina & & & \\
\hline Chosica & & & \\
\hline Cieneguilla & & & \\
\hline
\end{tabular}

Fuente: Cedro. El problema de las drogas en el Perú, 2011. Elaboración propia.

\section{Distribución del riesgo por distritos en Lima}

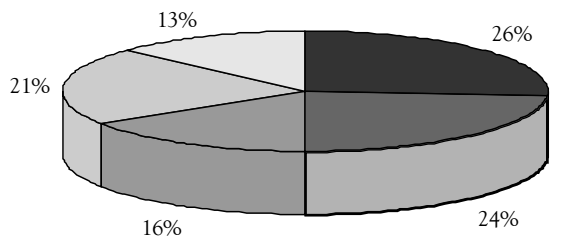

Riesgo Alto

Riesgo Medio Alto Riesgo Medio

Riesgo Bajo Medio

Riesgo Bajo 
Riesgo en materia de PLA por zona geográfica - Lima (distritos)

1 - CENTRO DE LIMA

2 - CARMEN DE LALEGUA

3 - ATE

4- BARRANCO

5 - BRENAA

6 - VENTANILLA

7 - COMAS

8. LAPERLA

9 - CHORRILLOS

10 - ELAGUSTINO

11 - JESUS MARIA

12 - LAMOLINA

13- LA VICTORIA

14 - LINCE

15 - BELLAMSTA

16 - CALLAO CENTRO

17 - MAGDALENA

18 - MIRAFLORES

19 - ANCON

20 - CHOSICA

21 - PUEBLO LIBRE

22 - PUENTE PIEDRA

23 - CIENEGUILLA

25 - RIMAC

27 - SAN ISIDRO

28 - INDEPENDENCIA

29 - SAN JUAN DE MIRAFLORES

30 - SAN LUIS

31 - SAN MARTIN DE PORRES

32 - SAN MIGUEL

33 - SURCO

34 - SURQUILLO

35 - VLLA MARIA DEL TRIUNFO

36 - SAN JUAN DE LURIGANCHO

38 - CARABAYLLO

39 - LOS OLNOS

41 - SAN BORIA

42 - VLLAEL SALVADOR

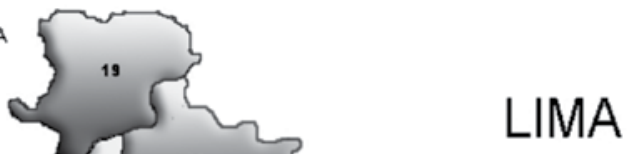

43 - SANTAANITA

\subsection{Transacciones}

\subsubsection{Regla de pago por medio de agencias del banco}

\begin{tabular}{|l|l|l|}
\hline $\begin{array}{c}\text { Rangos (dólares } \\
\text { americanos) }\end{array}$ & $\begin{array}{c}\text { Ponderación } \\
\text { total del ries@o } \\
(\%)\end{array}$ & $\begin{array}{c}\text { Nivel de ries@o } \\
\text { estadístico /juicio } \\
\text { experto }\end{array}$ \\
\hline $0-10,000$ & $\bigcirc$ & 4 \\
\hline $10,000-25,000$ & $\bigcirc$ & 3 \\
\hline $25,000-100,000$ & $\bigcirc$ & 3 \\
\hline $100,000-250,000$ & $\bigcirc$ & 2 \\
\hline$>250,000$ & $100.0 \%$ & - \\
\hline Total & & \multicolumn{2}{|l|}{} \\
\cline { 1 - 2 } & &
\end{tabular}

- Criterios para determinar la ponderación total del riesgo:

El criterio es contabilizar el número de transacciones realizadas, físicas o virtuales, por medio de la red de agencias del banco.

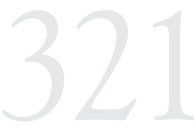

NI DEJAR HACER NI

DEJAR PASAR: EL

COMPROMISO DE

LAS INSTITUCIONES

BANCARIAS

PERUANAS FRENTE

AL LAVADO

DE ACTIVOS A

TRAVÉS DE LA

IMPLEMENTACIÓN

DE UNA

METODOLOGÍA

POR RIESGO

\section{DON'T LET IT}

HAPPEN NOR

LET IT GO: THE

COMMITMENT

OF PERUVIAN

BANKING

INSTITUTIONS

AGAINST MONEY

LAUNDERING

THROUGHTHE

IMPLEMENTATION

OF AN AML RISK

ASSESSMENT

METHODOLOGY 
3.5.2. Regla de pago por medio de transacciones bancarias

\begin{tabular}{|l|l|l|}
\hline \multicolumn{1}{|c|}{$\begin{array}{c}\text { Rangos (dólares } \\
\text { americanos) }\end{array}$} & \multicolumn{1}{|c|}{$\begin{array}{c}\text { Ponderación } \\
\text { total del } \\
\text { riesgo (\%) }\end{array}$} & \multicolumn{1}{|c|}{$\begin{array}{c}\text { Nivel de riesgo } \\
\text { estadístico / juicio } \\
\text { experto }\end{array}$} \\
\hline $0-10,000$ & $\bigcirc$ & 4 \\
\hline $10,000-25,000$ & $\bigcirc$ & 3 \\
\hline $25,000-100,000$ & $\bigcirc$ & 3 \\
\hline $100,000-250,000$ & $\bigcirc$ & 2 \\
\hline$>250,000$ & $\bigcirc$ & 2 \\
\hline Total & $100.00 \%$ & \\
\cline { 1 - 2 } & &
\end{tabular}

- Criterios para determinar la ponderación total del riesgo:

El criterio es contabilizar el número de instrucciones de cargo realizados en las cuentas de los clientes en el banco para cada rango. Se contabilizarán todos los cargos en las cuentas de clientes del banco.

En el caso propuesto, podemos observar que la empresa JJK fue constituida hace muy poco tiempo (2 años) en el país. Esto implica que, desde el puntos de vista de la prevención de LA/FT, tiene un riesgo mayor que aquellas otras con más años de existencia en el mercado, que tiene mucho más que perder en el supuesto de verse envuelta en un caso de lavado de activos por el riesgo reputación que debe defender y al mismo tiempo por tener más información que permite explicar sus operaciones. Sobre su objeto social, debemos indicar que el simple hecho de dedicarse a la elaboración de productos farmacéuticos hace que sea mayor su riesgo en LA/FT, pues muchos de los insumos que utiliza podrían ser tóxicos para la salud pública, aún cuando para la legislación nacional pueda ser considerada por el objeto social como sujeto obligado en PLA/FT que deberá contar con políticas y procedimientos para la prevención de LA/FT, el riesgo se mantiene. Por otro lado, los productos bancarios que utiliza en muchos casos para nuestro medio como país son de la mediana o gran empresa, ello implica que debe conocerse perfectamente el rango de sus operaciones para que las mismas sean calificadas como usuales. Sobre el segmento al cual pertenece la empresa, en relación con otras de igual o similar actividad económica, el propósito es determinar el grado de homogeneidad y heterogeneidad. 
El hecho que realice operaciones en América Latina y, en especial, con un paraíso financiero implica un alto riesgo automático, pues las generalizaciones son lo que muchas veces nos hace daño y es algo que debe evitarse para mantener un buen sistema de prevención de LA/FT. Es necesario determinar si el propósito de mantener relaciones comerciales se vincula con empresas, personas naturales o el mismo Estado que justifique dentro de la política de conocimiento la razón de ser de las cosas. En relación con la composición de su accionariado, el $80 \%$ del capital de la empresa consta de acciones al portador. Esto nos hace suponer que la empresa no puede brindar el nombre del accionista (persona natural) que representa ese $80 \%$. En este caso, el anonimato de su accionariado no es bueno e implica ocultar la identidad del beneficiario final de la empresa, lo cual, por sí solo, es calificado como de riesgo alto.

\section{Mitigantes del riesgo}

- Se debe llevar a cabo la validación de los datos de los clientes en el proceso de inicio de relación con el banco de datos de personas que están siendo investigadas por delitos de corrupción, tráfico ilícito de drogas, narcotráfico, micro comercialización, lavado de activos y terrorismo, a fin de aplicar la debida diligencia reforzada en estos casos.

- Se debe utilizar programas de búsquedas masivas en un sistema web que realiza la comparación del nombre y apellido de un cliente contra los nombres de personas de una base negativa a nivel mundial. En caso de encontrar coincidencias, se generan alertas. Este programa permite visualizar las coincidencias, registrar y documentar el análisis realizado por la unidad de prevención de lavado de activos, así como generar reportes de las alertas recibidas, atendidas y pendientes.

- Es necesario monitorear las calificaciones realizadas por los funcionarios de negocios diariamente, a fin de detectar operaciones que pudieran relacionarse con actos de corrupción, lavado de activos o financiamiento del terrorismo.

\section{Procedimiento a seguir en el cierre de casos generados}

Sobre la base de la Matriz de Riesgo de Prevención del Lavado de Activos, debemos señalar que el procedimiento a seguir en el cierre de casos generados estará basado en el grado o nivel de riesgo que representa cada cliente. Es importante mencionar que para el análisis

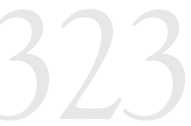

NI DEJAR HACER NI DEJAR PASAR: EL COMPROMISO DE LAS INSTITUCIONES BANCARIAS

PERUANAS FRENTE AL LAVADO

DE ACTIVOS A

TRAVÉS DE LA IMPLEMENTACIÓN DE UNA

METODOLOGÍA POR RIESGO

DON'T LET IT

HAPPEN NOR

LET IT GO:THE

COMMITMENT

OF PERUVIAN

BANKING

INSTITUTIONS

AGAINST MONEY

LAUNDERING

THROUGHTHE IMPLEMENTATION OF AN AML RISK ASSESSMENT METHODOLOGY 
de los factores de riesgos hemos utilizado el método de análisis de probabilidad / impacto y el juicio experto.

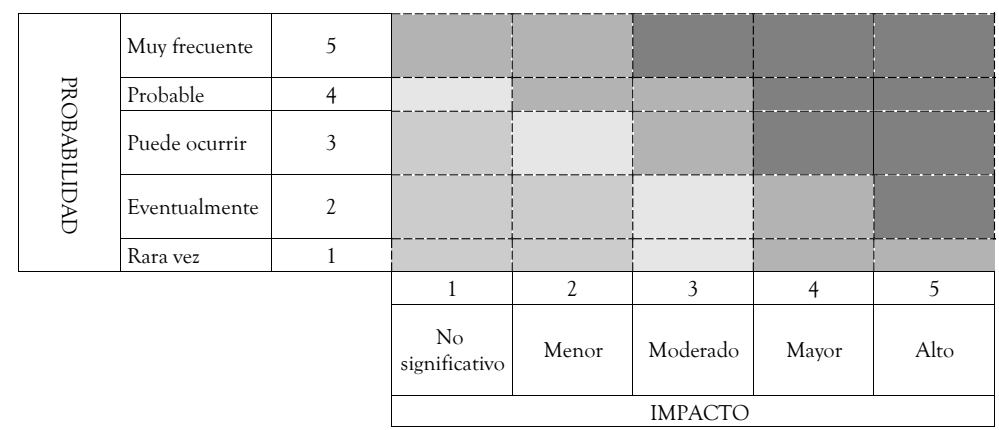

\subsection{Cierre de casos generados en el sistema de monitoreo}

5.1.1. Revisión y documentación que se debe adjuntar a la una unidad de prevención de lavado de activos por los casos generados a través de la regla de pago por medio de agencias del banco sobre la base del riesgo identificado

- Validación en la base de datos del Ministerio Público y del Poder Judicial.

- Si la transacción fuera menor a 10000 dólares americanos, adjuntar Registro de Operaciones Única ${ }^{19}$ (ROU), el mismo que debe señalar claramente el origen de los fondos.

- RENIEC.

- Validación en la base de datos del Ministerio Público y del Poder Judicial.

- Si la transacción fuera mayor a 10000 dólares americanos, adjuntar ROU, el mismo que debe señalar claramente el origen de los fondos y que se cuenta con la documentación de sustento; caso contrario, solicitar información al personal de agencia del banco que haya realizado la transacción.

- RENIEC.

- Validación en la base de datos del Ministerio Público y del Poder Judicial, consulta de saldos y movimientos.

- Si la transacción fuera mayor a 10000 dólares americanos, adjuntar ROU, el mismo que debe señalar claramente el origen de los fondos y que se cuenta con la documentación de sustento;

19 El Registro de Operaciones Únicas (ROU) es un tipo de control que ejecuta la entidad bancaria para identificar al tramitante, ordenante y beneficiario de la operación, por monto igual o superior a 10 000 dólares americanos sin importar que la misma si la operación se realiza en efectivo o por medio virtual, o a través de terceros. 
caso contrario, solicitar información al personal de agencia del banco que haya realizado la transacción.

- RENIEC.

- Coordinar con el funcionario de negocios titular de la cuenta, solicitando mayor información de la transacción realizada por el cliente, en concordancia con lo establecido en la Política de Conocimiento de Cliente, en caso amerite.

- Validación en la base de datos del Ministerio Público y del Poder Judicial, consulta de saldos y movimientos.

- Si la transacción fuera mayor a 10000 dólares americanos, adjuntar ROU, el mismo que debe señalar claramente el origen de los fondos y que se cuenta con la documentación de sustento; caso contrario, solicitar información al personal de agencia del banco que haya realizado la transacción o a la unidad de prevención de lavado de activos.

- RENIEC.

- Coordinar con el funcionario de negocios titular de la cuenta, solicitando mayor información de la transacción realizada por el cliente, en concordancia con lo establecido en la Política de Conocimiento de Cliente, en caso amerite.

- Validación en la base de datos del Ministerio Público y del Poder Judicial, consulta de saldos y movimientos.

- Si la transacción fuera mayor a 10000 dólares americanos, adjuntar ROU, el mismo que debe señalar claramente el origen de los fondos y que se cuenta con la documentación de sustento; caso contrario, solicitar información al personal de agencia del banco que haya realizado la transacción o a la unidad de prevención de lavado de activos.

- RENIEC.

- Coordinar por medio de un correo electrónico con el funcionario de la cuenta solicitando mayor información de la transacción realizada por el cliente, en concordancia con lo establecido en la Política de Conocimiento de Cliente, en caso amerite.

5.1.2. Revisión y documentación que debe adjuntar a la unidad de prevención de lavado de activos por los casos generados a través de la Regla de Forma Pago por medio de transacciones bancarias, sobre la base del riesgo identificado

- Validación en la base de datos del Ministerio Público y del Poder Judicial.

NI DEJAR HACER NI

DEJAR PASAR: EL

COMPROMISO DE

LAS INSTITUCIONES

BANCARIAS

PERUANAS FRENTE

AL LAVADO

DE ACTIVOS A

TRAVÉS DE LA

IMPLEMENTACIÓN

DE UNA

METOdOlogía

POR RIESGO

DON'T LET IT

HAPPEN NOR

LET IT GO:THE

COMMITMENT

OF PERUVIAN

BANKING

INSTITUTIONS

AGAINST MONEY

LAUNDERING

THROUGHTHE

IMPLEMENTATION

OF AN AML RISK

ASSESSMENT

METHODOLOGY 
- Si la transacción fuera menor a 10000 dólares americanos, adjuntar ROU, el mismo que debe señalar claramente el origen de los fondos y que se cuenta con la documentación de sustento.

- Validación en la base de datos del Ministerio Público y del Poder Judicial.

- Si la transacción fuera menor a 10000 dólares americanos, adjuntar ROU, el mismo que debe señalar claramente el origen de fondos y que se cuenta con la documentación de sustento.

- Coordinar por medio de un correo electrónico con el funcionario de negocios solicitando mayor información de la transacción realizada por el cliente, en concordancia con lo establecido en la Política de Conocimiento de Cliente y de Mercado, en caso amerite.

- Validación en la base de datos del Ministerio Público y del Poder Judicial.

- Si la transacción fuera mayor a 10000 dólares americanos, adjuntar el ROU, el mismo que debe señalar claramente el origen de los fondos y que se cuenta con la documentación de sustento; este documento podrá ser generado unilateralmente por el funcionario de negocios sobre la base de la política de conocimiento del cliente, considerando que, por la naturaleza del negocio, en la mayoría de casos las transacciones son instruidas a través de órdenes telefónicas, por lo que no será posible que el cliente firme un documento.

- Correo del funcionario de negocios brindando mayor información en aplicación a la Política de Conocimiento de Cliente, en caso amerite.

- Validación en la base de datos del Ministerio Público y del Poder Judicial.

- Si la transacción fuera mayor a 10000 dólares americanos, adjuntar el ROU, el mismo que debe señalar claramente el origen de los fondos y que se cuenta con la documentación de sustento; este documento podrá ser generado unilateralmente por el funcionario de negocios sobre la base de la política de conocimiento del cliente.

- Correo del funcionario de negocios brindando mayor información en aplicación de la Política de Conocimiento de Cliente, en caso amerite.

- Validación en la base de datos del Ministerio Público y del Poder Judicial.

- Si la transacción fuera mayor a 10000 dólares americanos, adjuntar el ROU, el mismo que debe señalar claramente el 
origen de los fondos y que se cuenta con la documentación de sustento; este documento podrá ser generado unilateralmente por el funcionario de negocios sobre la base de la política de conocimiento del cliente.

- Correo del funcionario de negocios brindando mayor información en aplicación de la Política de Conocimiento de Cliente, en caso amerite.

En caso de ser PEP, adjuntar documentación (Declaración de Origen de Fondos y Hoja de Evaluación de Clientes Sensibles).

De encontrar en el banco de datos del Ministerio Público o del Poder Judicial información relacionada al lavado de activos, se debe solicitar el descargo correspondiente al cliente a través del funcionario de negocios. De continuar con el vínculo comercial, deben remitir a la unidad de prevención de lavado de activos el formato «Hoja de Evaluación de Clientes Sensibles». En caso de ubicar información de otros tipos de procesos de investigación, se ha de comunicar a la unidad de cumplimiento regulatorio del banco.

En caso de ser un cliente que encaje en la definición de un Sujeto Obligado, se deberá adjuntar la Declaración Jurada (DJ) de contar o no con un Oficial de Cumplimiento inscrito ante la Unidad de Inteligencia Financiera. De no contar con dicha DJ, se ha de solicitar al funcionario de negocios titular de la cuenta la hoja de evaluación (HECS).

En el caso propuesto de la empresa JJK y el Banco Buena Fe, aplicando la metodología propuesta deberíamos, habría que lo siguiente: las transacciones que viene ejecutando la empresa muestran un nivel de riesgo alto para el Banco Buena Fe. Asimismo, las transacciones no han sido razonablemente justificadas por la empresa, lo que amerita reportar a la UIF-Perú por transacción sospechosa de lavado de activos, con el propósito de que efectúe las indagaciones del caso para su posterior informe técnico al Ministerio Público si lo estima apropiado.

\section{CONCLUSIONES}

1. El riesgo de prevención de lavado de activos es la posibilidad de que la empresa bancaria sea utilizada por terceros para fines de ocultar dinero de origen ilícito o de terrorismo.

2. Contar con una metodología por riesgo en prevención de lavado de activos constituye un instrumento que forma parte del sistema

NI DEJAR HACER NI DEJAR PASAR: EL COMPROMISO DE LAS INSTITUCIONES BANCARIAS

PERUANAS FRENTE AL LAVADO

DE ACTIVOS A

TRAVÉS DE LA

IMPLEMENTACIÓN

DE UNA

metodología

POR RIESGO

DON'T LET IT

HAPPEN NOR

LET IT GO:THE

COMMITMENT

OF PERUVIAN

BANKING

INSTITUTIONS

AGAINST MONEY

LAUNDERING

THROUGHTHE

IMPLEMENTATION

OF AN AML RISK

ASSESSMENT

METHODOLOGY 
de prevención de lavado de activos. Este incluye el conocimiento del cliente, mercado, la capacitación del personal, la aplicación de las normas de prevención de lavado de activos como política empresarial.

3. La metodología de identificación y evaluación del riesgo de lavado de activos implica que las entidades del sistema financiero apliquen las normas respectivas de su país y, adicionalmente, empleen recursos propios en identificar sus propios riesgos, estableciendo mecanismos que les permitan la oportuna detección de transacciones que representen un riesgo de lavado.

4. La principal herramienta para la identificación y evaluación del riesgo es la aplicación del principio de conocimiento del cliente, no solo de acuerdo con las normas nacionales, sino también de acuerdo con las recomendaciones de los organismos internacionales más relevantes en el tema.

5. Las empresas bancarias nacionales promueven un sistema financiero sólido, competitivo y confiable mediante la implementación de una metodología de identificación y evaluación por riesgo en prevención de lavado de activos.

\section{REFERENCIAS}

ADN Paraguayo (22 de junio de 2016). Desmantelan red de corrupción en la operación «lava jato». Recuperado de http://www.adndigital.com.py/ desmantelan-red-de-corrupcion-en-la-operacion-lava-jato/

Cedro (2011). El problema de las drogas en el Perú. Lima: autor.

Claessens, S. \& Yurtoglu, B. (2012). Corporate Governance and Development - An Update. Focus 10. Washington D.C.: IFC. Recuperado de http://www. ifc.org/wps/wcm/connect/d1fbde804b0a8281bd45bd77fcc2938e/Focus10_ CG\%26Development.pdf?MOD=AJPERES

El Confidencial (9 de agosto de 2016). Italia cierra filial de PrivatBank por violar normas de lavado de capitales. Recuperado de http://www.elconfidencial.com/ ultima-hora-en-vivo/2016-08-09/italia-cierra-filial-de-privatbank-por-violarnormas-de-lavado-de-capitales_985923/

Encuesta Pulso Perú: Mapa de la corrupción en el país (11 de octubre de 2016). Gestión. Recuperado de https://gestion.pe/peru/politica/encuesta-pulso-perumapa-corrupcion-pais-117625

Flores Konja, J.V. \& Rozas Flores, A.E. (2008). El gobierno corporativo: un enfoque moderno. Quipukamayoc, 15(29), 7-22. doi: http://dx.doi.org/10.15381/ quipu.v15i29.2065

Gestión (11 de octubre de 2016). El 45\% admite que los peruanos son muy tolerantes frente a la corrupción política. Recuperado de https://gestion.pe/peru/ politica/45-admite-peruanos-son-tolerantes-frente-corrupcion-politica-117636 
Grupo de Acción Financiero Internacional (GAFI) (2014). Guía para un enfoque basado en riesgo: el sector bancario. París: GAFI/OCDE.

Haza de la, A. (2010). Los bancos y la responsabilidad social como medición de éxito. Revista Derecho PUCP, 64, 325-332.

Jiménez Villarejo, C. (2003). La Corrupción. El Ciervo, 52 (633), 10-13.

NI DEJAR HACER NI

DEJAR PASAR: EL

COMPROMISO DE

Lamas Puccio, L. (2007) Lavado de Activos y Financiación del Terrorismo. Lima, Perú: Editorial Jurídica Griley.

López Valera, I. (2014). Delitos de lavado de activos. Recuperado de http://www. voltairenet.org/article184439.html

Observatorio de Criminalidad (2011). El crimen y la violencia en cifras, 2008, 2009, 2010 y 2011. Lima: autor.

Paucas, M. (2013). La investigación del delito de lavado de activos: Tipologías y jurisprudencia. Lima: ARA.

Perú21 (17 de marzo de 2015). Hugo Chávez: Investigan en España a ex altos cargos chavistas por blanqueo. Recuperado de https:/peru21.pe/mundo/hugochavez-investigan-espana-ex-altos-cargos-chavistas-blanqueo-171947

Superintendencia de Banca, Seguros y AFP (SBS) (enero-marzo de 2017). Información estadística: Unidad de Inteligencia Financiera del Perú. Recuperado de https://www.sbs.gob.pe/Portals/5/jer/est_op201703/20170502_ BolEst-Marzo2017.pdf

Toso, Á. (2014). Prevención del lavado de activos y crédito documentario: iA quién debe conocer el banco emisor? Una respuesta desde el derecho privado. Revista de Derecho (Universidad Católica del Norte), 21 (2), 401-436. doi: 10.4067/ S0718-97532014000200012

Varela, E. \& Venini, A. (2007). Normas sobre prevención de lavado de activos en Argentina: su impacto sobre la actividad bancaria y aseguradora. Invenio, 10(19), 73-92.

LAS INSTITUCIONES

BANCARIAS

PERUANAS FRENTE

AL LAVADO

DE ACTIVOS A

TRAVÉS DE LA

IMPLEMENTACIÓN

DE UNA

METOdOLOGÍA

POR RIESGO

DON'T LET IT

HAPPEN NOR

LET IT GO:THE

COMMITMENT

OF PERUVIAN

BANKING

INSTITUTIONS

AGAINST MONEY

LAUNDERING

THROUGHTHE

IMPLEMENTATION

OF AN AML RISK

ASSESSMENT

METHODOLOGY

Villegas, C. (1999). Compendio jurídico, técnico y práctico de la actividad bancaria: La actividad bancaria. Buenos Aires: Depalmea.

Zavaleta, M. \& Speer, A. (2012). FATCA: Entre la búsqueda de los «peces gordos» y los límites jurídicos de América Latina en la fiscalidad internacional. Revista Peruana de Derecho Tributario, 6(17). Recuperado de http://www.derecho. usmp.edu.pe/CET_ediciones_anteriores/edicion_17/doctrina/17/FATCA_ RPDT_USMP_Nōī.pdf

\section{Jurisprudencia, normativa y otros documentos legales}

Comité de Supervisión Bancaria de Basilea (BCBS) (2012). Principios Básicos para una supervisión bancaria eficaz. Recuperado de https://www.bis.org/publ/ bcbs230_es.pdf

Constitución Política del Perú (1993). 
Convención de las Naciones Unidas contra el Tráfico Ilícito de Estupefacientes y Sustancias Sicotrópicas (Viena, 19 de diciembre de 1988), United Nations Treaty Series 1582(I-27627), 303-349.

Decreto legislativo n. ${ }^{\circ}$ 1104, Decreto legislativo que modifica la legislación sobre pérdida de dominio, Diario Oficial El Peruano, 19 de abril de 2012, 464370-464377.

Decreto legislativo n. ${ }^{\circ}$ 1106, Decreto legislativo de lucha eficaz contra el lavado de activos y otros delitos relacionados a la minería ilegal y crimen organizado, Diario Oficial El Peruano, 19 de abril de 2012, 464381-464389.

Decreto legislativo n. ${ }^{\circ}$ 1249, Diario Oficial El Peruano, 26 de noviembre de 2016, 605158-605162.

Decreto supremo n..$^{\circ}$ 018-2006-JUS, Aprueban Reglamento de la Ley № 27693, Ley que crea la Unidad de Inteligencia Financiera del Perú, UIF - Perú, Diario Oficial El Peruano, 25 de julio de 2006, 324977-324985.

Decreto supremo n. ${ }^{\circ}$ 057-2011-PCM, Decreto Supremo que Aprueba el Plan Nacional de Lucha contra el Lavado de Activos y el Financiamiento del Terrorismo y la Creación de la Comisión Ejecutiva Multisectorial contra el Lavado de Activos y el Financiamiento del Terrorismo, Diario Oficial El Peruano, 01 de julio de 2011, 445676-445678.

Ley 26702, Ley General del Sistema Financiero y del Sistema de Seguros y Orgánica de la Superintendencia de Banca y Seguros, Diario Oficial El Peruano, 09 de diciembre de 1996, Separata Especial, 144950-145012.

Ley 27693, Ley que crea la Unidad de Inteligencia Financiera - Perú, Diario Oficial El Peruano, 12 de abril de 2002, 221209-221213.

Ley 28306, Ley que modifica artículos de la ley n. . 27693, Diario Oficial El Peruano, 29 de julio de 2004, 273521-273528.

Plan Nacional de Lucha contra el Lavado de Activos y el Financiamiento del Terrorismo (2011). Recuperado de http://www.sbs.gob.pe/Portals/5/jer/plan_nac_ laft/files/Plan_Nacional_ALA_CFT_DS_057-2011-PCM.pdf

Resolución CONASEV No 033-2011-EF/94.01.1, Normas para la Prevención del Lavado de Activos y Financiamiento del Terrorismo, Diario Oficial El Peruano, 22 de mayo de 2011, Separata Especial, 442986-443008.

Resolución SBS n. $2660-2015$, Reglamento de Gestión de Riesgos de Lavado de Activos y del Financiamiento del Terrorismo, Diario Oficial El Peruano, 18 de mayo de 2015, Separata Especial, 552737-552758.

Resolución SBS n. ${ }^{\circ}$ 4349-2016, Aprueban Norma sobre funciones y cargos ocupados por personas expuestas políticamente (PEP) en materia de prevención del lavado de activos y del financiamiento del terrorismo, Diario Oficial El Peruano, 14 de agosto de 2016, 596809-596810. 
Resolución SMV No 007-2013-SMV/01, modifican Normas para la Prevención del Lavado de Activos y Financiamiento del Terrorismo aprobadas por Res. N ${ }^{\circ}$ 033-2011-EF/94.01.1, Diario El Peruano, 25 de marzo de 2013, 491507-491516.

Superintendencia de Banca, Seguros y AFP (SBS) \& Banco Interamericano de Desarrollo (BID) (2016). Evaluación Nacional de Riesgos de Lavado de Activos y Financiamiento del Terrorismo: República del Perú. Resumen Ejecutivo. Recuperado de http://www.sbs.gob.pe/Portals/5/jer/ESTUDIO-ANALISISRIESGO/20170420_EVNARETER.pdf

NI DEJAR HACER NI DEJAR PASAR: EL

COMPROMISO DE

LAS INSTITUCIONES

BANCARIAS

PERUANAS FRENTE

Recibido: 28/06/2017 Aprobado: 06/03/2018

AL LAVADO

DE ACTIVOS A
TRAVÉS DE LA

IMPLEMENTACIÓN

DE UNA

METODOLOGÍA

POR RIESGO

DON'T LET IT

HAPPEN NOR

LET IT GO: THE

COMMITMENT

OF PERUVIAN

BANKING

INSTITUTIONS

AGAINST MONEY

LAUNDERING

THROUGHTHE

IMPLEMENTATION

OF AN AML RISK

ASSESSMENT

METHODOLOGY 